Check for updates

Cite this: RSC Adv., 2017, 7, 22757

Received 12th January 2017 Accepted 10th April 2017

DOI: $10.1039 / c 7 r a 00520 b$

rsc.li/rsc-advances

\section{Assessing the effective factors affecting the conformational preferences and the early and late transition states of the unimolecular retro-ene decomposition reactions of ethyl cyanate, ethyl thiocyanate and ethyl selenocyanate $\uparrow$}

\begin{abstract}
Hooshang Atabaki, ${ }^{a}$ Davood Nori-Shargh (ID *b and Mohamad Momen-Heravi ${ }^{a}$
The structural and conformational properties of ethyl cyanate (1), ethyl thiocyanate (2), and ethyl selenocyanate (3) and also their corresponding unimolecular retro-ene decomposition and isomerization reactions were investigated by means of G3(MP2) and MP2/6-311++G** methods and natural bond orbital interpretations. We assessed the role and contributions of the hyperconjugative interactions on the conformational preferences of compounds 1-3 by the deletion of the orbitals overlapping from the Fock matrices of the gauche- and anti-conformations, where the results obtained showed that the deletion of these hyperconjugative interactions from the Fock matrices leads to an increase in the anticonformations preferences, revealing the significant impacts of the hyperconjugative interactions on the gauche-conformations preferences going from compound 1 to compound 3 . The hyperconjugative interactions, Pauli exchange-type repulsions (PETR), and electrostatic model associated with the dipoledipole interactions were in favor of the gauche-conformation of compound 1 . Contrary to the conclusions published in the literature, there is no fact that justifies the anti-conformation preference in compound 1. Accordingly, we concluded that there are two rotamers (i.e., gauche- and anticonformations) with literally the same populations for compound 1 . The unimolecular retro-ene decomposition reactions of compounds 1-3 were more feasible than their corresponding cyanate $\rightarrow$ isocyanate isomerization reactions. The Pauli exchange-type repulsions have determining impacts on the retro-ene decomposition reactions of these compounds. The correlations between the activation Gibbs free energies and the advancements of the transition states $\left(\delta B_{\mathrm{av}}\right)$ of the retro-ene decomposition reactions of compounds 1-3 according to the Hammond-Leffler postulate were also analyzed. Interestingly, the variations of the bond lengths in the transition state structures of the retro-ene decomposition reactions of compounds 1-3 were in accordance with the Hammond-Leffler postulate.
\end{abstract}

\section{Introduction}

Organyl cyanates and their thio- and seleno-analogs (as ambient functional groups) are widely used in the pharmaceutical industry, medicine, organic synthesis, etc. $^{1-3}$ It is worth noting that the thiocyanate anion could be converted to the hypothiocyanite ion $\left(\mathrm{OSCN}^{-}\right)$in the human body, which is an antibiotic. The lactoperoxidase system is effective against staphylococci, Escherichia coli, and pseudomonads. ${ }^{4-6}$ It uses hydrogen peroxide to catalyze oxidation of the thiocyanate

${ }^{a}$ Department of Chemistry, College of Science, Islamic Azad University, Mashhad Branch, Mashhad, Iran

${ }^{b}$ Department of Chemistry, College of Science, Islamic Azad University, Arak Branch, Arak,Iran.E-mail: D-norishargh@iau-arak.ac.ir;nori_ir@yahoo.com

$\dagger$ Electronic supplementary information (ESI) available. See DOI: 10.1039/c7ra00520b anion to the antibiotic to function in the airway lumen. The antileshmanial potential of selenocyanates has also been assayed and established. ${ }^{7}$

Since cyanates and their thio- and seleno-analogs play important roles in human safety and organic syntheses, the exploration of effective factors on the structural and conformational behaviors of their organyl derivatives could be of interest to synthetic and theoretical chemists. Due to the instability of covalent (organyl) cyanates, ${ }^{8-14}$ there is little published information about their structures..$^{15-18}$

Sakaizumi and co-workers performed microwave spectroscopy to investigate the conformational behavior of ethyl cyanate (1) and, based on their results, the anti-conformation of compound 1 was found to be more stable than its gaucheconformation..$^{18}$ They claimed that they could not calculate the energy difference between the anti- and gauche-conformations of ethyl cyanate due to the weakness of the lines from the 
gauche-conformation. In addition, due to the insufficient number of isotope substituents, no geometrical data could be derived. ${ }^{\mathbf{1 8}}$

In 1998, Leszczynski and co-workers performed $a b$ initio calculations at the MP2 level of theory with a triple- $\zeta$ basis set augmented with polarization and diffusion functions to investigate the structure and conformational stability of ethyl cyanate (1). ${ }^{19}$ In addition, they investigated the relative stabilities of the rotational conformers of compound 1 at the MP4 level using MP2 optimized reference geometries. Based on the results obtained, they pointed out that the anti-conformation of compound 1 was predicted to be slightly more stable $(0.14 \mathrm{kcal}$ $\mathrm{mol}^{-1}$ ) than its gauche-conformation. ${ }^{19}$

In 2003, Pasinszki and co-workers performed mid-infrared spectroscopy and quantum mechanical calculations to study the structure, conformation, and isomerization of gaseous ethyl cyanate (1), ${ }^{20}$ and their results indicated the presence of two conformations of ethyl cyanate in gas phase, the gauche-and the anti-conformations. Also, they mentioned that the anti-conformation of ethyl cyanate is more stable than its gauche-conformation by about $0.16 \mathrm{kcal} \mathrm{mol}^{-1}$ (as calculated at the $\operatorname{CCSD}(\mathrm{T}) / 6$ $311+\mathrm{G}(2 \mathrm{~d}, 2 \mathrm{p}) / / \mathrm{B} 3 \mathrm{LYP} / 6-311+\mathrm{G}(2 \mathrm{~d}, 2 \mathrm{p})$ level of theory), which is similar to the result obtained by Leszczynski and co-workers. ${ }^{19}$ It is worth noting that Pasinszki and co-workers ${ }^{20}$ mentioned that the conversion of ethyl thiocyanate to its isothiocyanate isomer in the gas phase could not be take place via a unimolecular process at ambient temperature [B3LYP/6-311+G(2d,2p): $\left.\Delta G_{\text {(ethyl cyanate } \rightarrow \text { ethyl isocyanate })}^{\neq}=52.31 \mathrm{kcal} \mathrm{mol}^{-1}\right]$, which is in the line with the results obtained by Faustov and co-workers ${ }^{21}$ for methyl cyanate [G2(MP2, SVP): $\Delta G_{(\text {methyl cyanate } \rightarrow \text { methyl isocyanate })}^{\neq}=$ $\left.62.6 \mathrm{kcal} \mathrm{mol}^{-1}\right]$.

In addition to ethyl cyanate (1), the conformational behavior of ethyl thiocyanate (2) has been the subject of several infrared, Raman, and microwave investigations. ${ }^{22-27}$ In 1964, Hirschmann and co-workers performed infrared spectroscopy to study the conformational properties of the liquid and solid states of ethyl thiocyanate (2) and they concluded that the molecule exists in the gauche- and anti-conformations. ${ }^{22}$ They calculated an enthalpy difference of $0.49 \pm 0.03 \mathrm{kcal} \mathrm{mol}^{-1}$ between the more stable anti- and higher energy gauche-conformations.

Contrary to the conclusion obtained by Hirschmann and coworkers concerning the anti-conformation preference in ethyl thiocyanate (2), the microwave spectrum analysis of this compound (by Bjørseth and Marstokk) revealed only one rotational isomer (the gauche-conformation). ${ }^{23}$ The discrepancy between the results of the vibrational spectroscopy ${ }^{23}$ and the microwave investigations of ethyl thiocyanate $(2)^{23}$ prompted Ellestad and Torgrimsen to reevaluate the vibrational spectrum of this compound and their results showed only the gaucheconformation. $^{24}$

In 1984, Durig and co-workers reanalyzed the vibrational spectrum of gaseous and solid ethyl thiocyanate (2) and also the Raman spectra of its liquid and solid sates. ${ }^{25}$ From the variabletemperature Raman study of the liquid state of ethyl thiocyanate (2), they concluded that the gauche-conformation of ethyl thiocyanate (2) is more stable than its anti-conformation (an enthalpy difference of $\left.1.68 \pm 0.07 \mathrm{kcal} \mathrm{mol}^{-1}\right) .{ }^{25}$ In 1986,
Braathen and Gatial analyzed the infrared spectrum of ethyl thiocyanate (2) isolated in argon and nitrogen matrices at $12 \mathrm{~K}$ and they found that the gauche-conformation was about $1.0 \pm$ $0.07 \mathrm{kcal} \mathrm{mol}^{-1}$ more stable than its anti-conformation. ${ }^{26}$

To the best of our knowledge, there is only one report published outlining the rotational spectral data from the structural parameters of ethyl selenocyanate (3). ${ }^{27}$ Evaluations of the experimental data published about the conformational properties of ethyl cyanate (1), ethyl thiocyanate (2), and ethyl selenocyanate (3) imply an anti-conformation preference in compound $\mathbf{1}$ and the gauche-conformation preference in compounds 2 and $\mathbf{3}$, but there is no published information about the origin of the conformational behaviors of compounds 1-3.

The purpose of the present study was to explore the roles and contributions of the effective factors on the conformational behaviors of compounds 1-3 and also their retro-ene decomposition reactions, which take place earlier than their corresponding cyanate $\rightarrow$ isocyanate isomerization reactions. ${ }^{19,20}$ In this work, we examined the role and contributions of the generalized manifestation of the anomeric effect, ${ }^{28-48}$ the steric exchanges [total steric exchange energies, TSEE, which is considered to represent the Pauli exchange-type repulsions between filled orbitals (or the quasi-classical "Lennard-Jones repulsion") between hard-shell sphere atoms], ${ }^{49-53}$ the electrostatic model associated with the dipole-dipole interactions, and also the attractive electrostatic interactions between two adjacent atoms on the conformational preferences and unimolecular retro-ene decomposition reactions of compounds 1-3. Importantly, the potential energy surfaces of the retro-ene decomposition reactions of compounds 1-3 in accordance with the Hammond-Leffler postulate were analyzed and the correlations between the early and late transition state structures, the advancements of the transition states (the average bond orders values, $\delta B_{\mathrm{av}}$ ), and the steric effects associated with the Pauli exchange-type repulsions were explored.

In order to explore the contributions of the hyperconjugative interactions on the anomeric relationships in compounds 1-3, we deleted the $\mathrm{LP}_{1} \mathrm{X}_{3} \rightarrow \sigma_{\mathrm{C}_{4}-\mathrm{C}_{5}}^{*}, \mathrm{LP}_{2} \mathrm{X}_{3} \rightarrow \sigma_{\mathrm{C}_{4}-\mathrm{C}_{5}}^{*}, \mathrm{LP}_{1} \mathrm{X}_{3} \rightarrow$ $\sigma_{\mathrm{C}_{4}-\mathrm{H}_{6}}^{*}, \mathrm{LP}_{2} \mathrm{X}_{3} \rightarrow \sigma_{\mathrm{C}_{4}-\mathrm{H}_{7}}^{*}, \sigma_{\mathrm{C}_{4}-\mathrm{C}_{5}}^{*} \rightarrow \sigma_{\mathrm{X}_{3}-\mathrm{C}_{2}}^{*}, \sigma_{\mathrm{C}_{4}-\mathrm{H}_{7}}^{*} \rightarrow \sigma_{\mathrm{X}_{3}-\mathrm{C}_{2}}^{*}, \sigma_{\mathrm{X}_{3}-\mathrm{C}_{4}}$ $\rightarrow \sigma_{\mathrm{C}_{2}}^{*} \equiv \mathrm{N}_{1}, \sigma_{\mathrm{X}_{3}-\mathrm{C}_{4}} \rightarrow \pi_{\mathrm{C}_{2} \equiv \mathrm{N}_{1}}^{*}$, and $\sigma_{\mathrm{C}_{5}-\mathrm{H}_{8}} \rightarrow \sigma_{\mathrm{X}_{3}-\mathrm{C}_{4}}^{*} \quad$ hyperconjugative interactions [which are changed by the rotations around the $\mathrm{X}-\mathrm{CH}_{2}$ bonds, where $\mathrm{X}=\mathrm{O}(\mathbf{1}), \mathrm{S}(2)$, Se (3)] from the Fock matrices of the gauche- and anti-conformations. Then, by rediagonalization and comparison of the current Fock matrices with their original forms (Scheme 1), we evaluated the contributions of the hyperconjugation interactions mentioned above on the anomeric relationships in compounds 1-3. It is worth noting that the procedure mentioned above is an efficient approach and can be performed to evaluate the role and contributions of some specific hyperconjugative interactions on the conformational properties of chemical compounds. ${ }^{28,29,47}$

\section{Computational details}

The modified version of Gaussian-2 (G2), which uses secondorder Møller-Plesset perturbation theory 


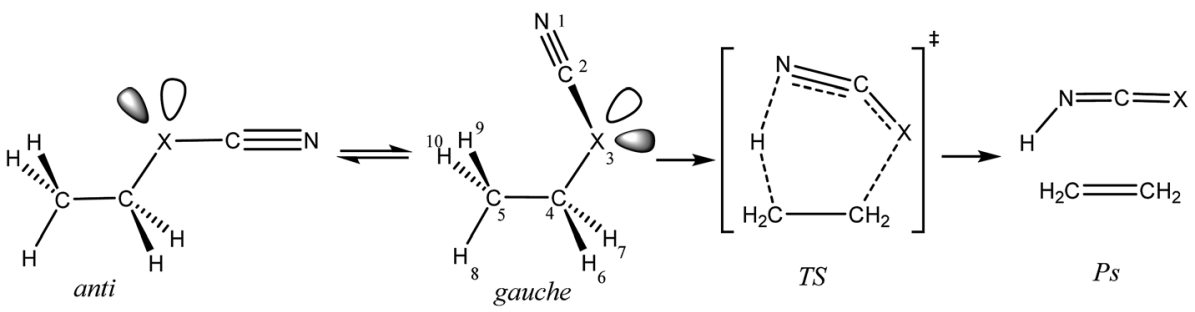

Scheme 1 Schematic representation of the gauche- and anti-conformations of compounds $1-3[X=O(1), S(2)$, Se (3)] and their corresponding unimolecular retro-ene decomposition reactions.

calculations $^{54-56}$ instead of MP4 for the basis set extension corrections, and also the MP2 method with the $6-311++\mathrm{G}^{* *}$ basis $\operatorname{set}^{57-65}$ on all atoms (MP2/6-311++G**) were performed to optimize the structural parameters of the gauche- and anticonformations and the transition state structures of the unimolecular retro-ene decomposition and cyanate $\rightarrow$ isocyanate isomerization reactions of compounds 1-3 and also to calculate their corresponding electronic energies and thermodynamic functions together with the GAMESS US package of programs. ${ }^{6,67}$

The natural bond orbital (NBO) interpretation was performed to examine quantitatively the impacts of the plausible hyperconjugative interactions and the Pauli exchange-type repulsions on the conformational and structural properties and also the potential energy surfaces of the retro-ene decomposition of compounds 1-3. In addition, the bonding and antibonding orbital occupancies and energies, the total natural resonance theory (NRT) bond orders (natural bond orders, nbo) of the gauche- and anti-conformations, and also the transition state structures of the retro-ene decomposition reactions of compounds 1-3 were analyzed by means of natural bond orbital interpretation with the NBO 5.G program. ${ }^{68}$

The stabilization energies (second-order perturbative estimations of donor-acceptor electronic interactions) in the NBO basis are inversely proportional to the energy differences between the donor $(i)$ and acceptor $(j)$ orbitals, $\Delta \varepsilon_{i j}$, and directly proportional to the magnitudes of the orbital overlap integrals $\left(S_{i j}\right){ }^{69-71}$

\section{Stabilization or resonance energy $\propto\left(S_{i j}{ }^{2} / \Delta \varepsilon_{i j}\right)$}

Accordingly, the stabilization or resonance energy (secondorder perturbational energies, $E_{2}$ ) associated with $i \rightarrow j$ electron delocalization can be explicitly estimated by the following equation:

$$
E_{2}=q_{i} \frac{F_{(i, j)}{ }^{2}}{\varepsilon_{j}-\varepsilon_{i}}
$$

where $q_{i}$ is the $i^{\text {th }}$ donor orbital occupancy, $\varepsilon_{i}$ and $\varepsilon_{j}$ are the orbital energies (diagonal elements), and $F_{(i, j)}$ is the off-diagonal natural bond orbital Fock matrix element. Note that the substantial desirable orbital overlapping can be reached by adjusting the corresponding off-diagonal terms when going from one compound to the next. ${ }^{72,73}$
The impacts of the hyperconjugative interactions (which change with the rotation around the $\mathrm{C}_{4}-\mathrm{X}_{3}$ bonds: $\mathrm{LP}_{1} \mathrm{X}_{3} \rightarrow \sigma_{\mathrm{C}_{4}-\mathrm{C}_{5}}^{*}, \mathrm{LP}_{2} \mathrm{X}_{3} \rightarrow \sigma_{\mathrm{C}_{4}-\mathrm{C}_{5}}^{*}, \mathrm{LP}_{1} \mathrm{X}_{3} \rightarrow \sigma_{\mathrm{C}_{4}-\mathrm{H}_{6}}^{*}, \mathrm{LP}_{2} \mathrm{X}_{3} \rightarrow$ $\sigma_{\mathrm{C}_{4}-\mathrm{H}_{7}}^{*}, \sigma_{\mathrm{C}_{4}-\mathrm{C}_{5}} \rightarrow \sigma_{\mathrm{X}_{3}-\mathrm{C}_{2}}^{*}, \sigma_{\mathrm{C}_{4}-\mathrm{H}_{7}} \rightarrow \sigma_{\mathrm{X}_{3}-\mathrm{C}_{2}}^{*}, \sigma_{\mathrm{X}_{3}-\mathrm{C}_{4}} \rightarrow \sigma_{\mathrm{C}_{2} \equiv \mathrm{N}_{1}}^{*}, \sigma_{\mathrm{X}_{3}-\mathrm{C}_{4}}$ $\rightarrow \pi_{\mathrm{C}_{2} \equiv \mathrm{N}_{1}}^{*}, \sigma_{\mathrm{C}_{5}-\mathrm{H}_{8}} \rightarrow \sigma_{\mathrm{X}_{3}-\mathrm{C}_{4}}^{*}$ electron delocalizations) on the conformational behaviors of compounds 1-3 were assessed by deletions of these electron delocalizations from the Fock matrices of their gauche- and anti-conformations (Fig. 1 and 2). It is worth noting that the natural bond orbital interpretation is a capable and sufficient theoretical approach to assess quantitatively the impacts of the hyperconjugative interactions associated with the electron delocalizations, the electrostatic interactions, and the steric effects on the dynamic behaviors and reactivity of chemical compounds. ${ }^{74}$

\section{Results and discussion}

\section{Conformational preference and retro-ene decomposition reactions in compounds 1-3}

The MP2/6-311++G** and G3MP2 calculated zero-point energies (ZPE), corrected zero-point energies $\left(E_{\mathrm{o}}=E_{\mathrm{el}}+\mathrm{ZPE}\right)$, enthalpy, entropy, Gibbs free energy, and their differences (i.e., $\Delta \mathrm{ZPE}$, $\Delta E_{\mathrm{o}}, \Delta H, \Delta S$ and $\Delta G$ ) for the gauche- and anti-conformations of compounds 1-3 and also their corresponding retro-ene decomposition reactions are summarized in Table 1 and ESI1. $\dagger$ According to the results of this work and the previously published data, there is no significant difference between the energies of the gauche- and anti-conformations of compound $\mathbf{1 .}$ Since the energy difference between the gauche- and anticonformations of compound $\mathbf{1}$ is negligible; we may expect the presence of two rotamers (i.e., gauche- and anti-conformations) at ambient temperature with literally the same populations for compound 1. In order to justify this claim, we examined the contributions of the stabilization energies associated with the hyperconjugative interactions, the electrostatic model associated with the dipole-dipole interactions, and the steric effects on the conformational behaviors of compound 1. Surprisingly, the factors mentioned above were in favor of the gaucheconformation of compound $\mathbf{1}$, contradicting the preference of the anti-conformation of compound $\mathbf{1}$ compared to its gaucheconformation. Therefore, the conclusion published in the literature concerning the anti-conformation preference in compound 1 could be questioned. ${ }^{18}$

The MP2/6-311++G** results showed that the gauche-conformation preference increases significantly from compound 1 to 

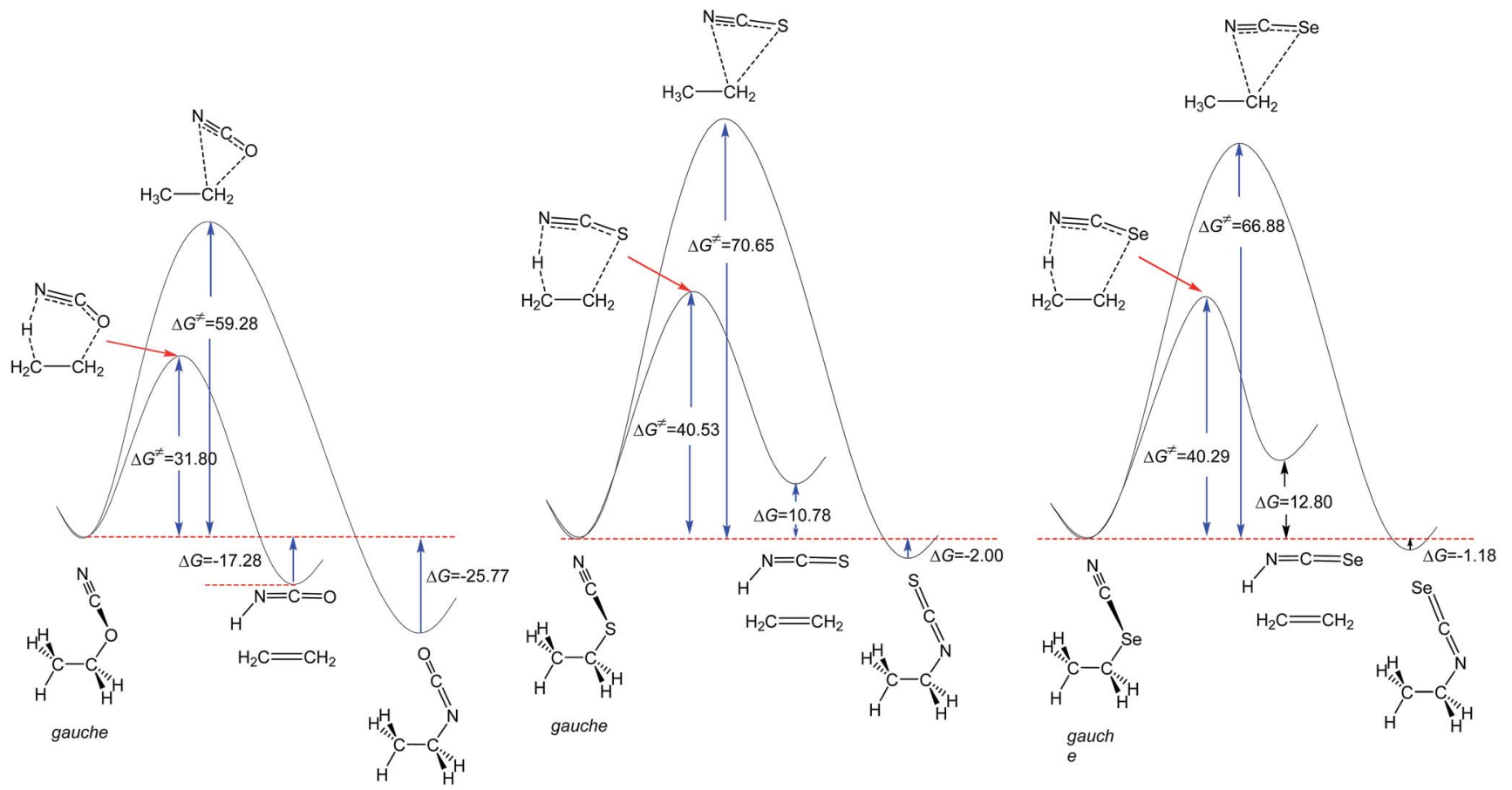

Fig. 1 MP2/6-311++G** calculated comparative potential energy profiles of the unimolecular isomerization and retro-ene decomposition reactions of compounds $1-3 . \Delta G$ and $\Delta G^{\ddagger}$ values are in $\mathrm{kcal} \mathrm{mol}^{-1}$.

compound 2, while it increase only slightly from compound 2 to compound 3. Seemingly, compared with the experimental data published about the conformational preferences in compounds 2 and $3,^{22-27}$ the $\mathrm{MP2} / 6-311++\mathrm{G}^{* *}$ method gives more reliable results concerning their conformational preferences than the results obtained at the G3(MP2) level (Table 1).
The results of this work (Fig. 1) and the previously published data indicate that the alkyl cyanate $\rightarrow$ alkyl isocyanate unimolecular isomerization reactions could not take place at ambient temperature. ${ }^{20,21}$ In this work, we examined the potential energy surfaces of the cyanate $\rightarrow$ isocyanate unimolecular isomerization reactions of compounds 1-3 (Fig. 1) and

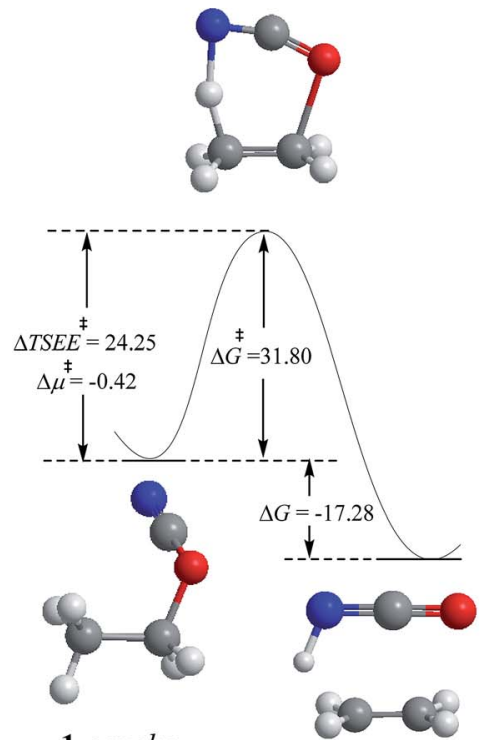

1-gauche

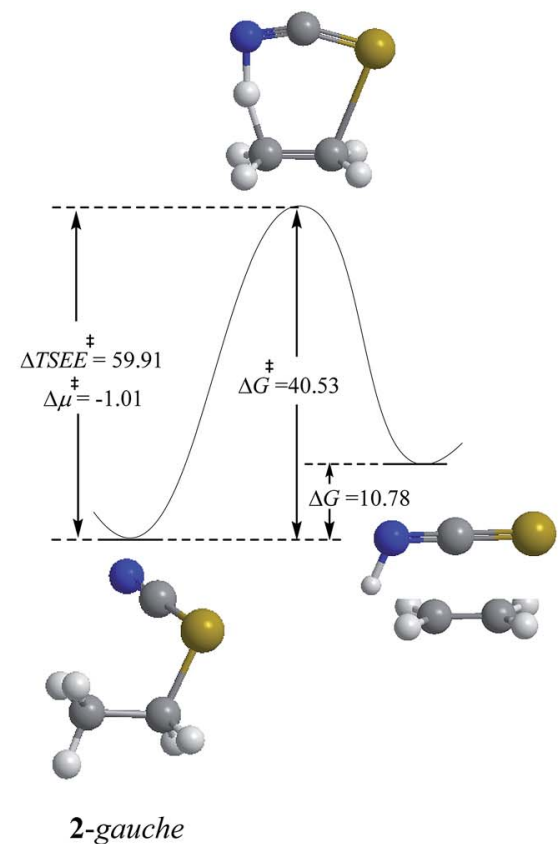

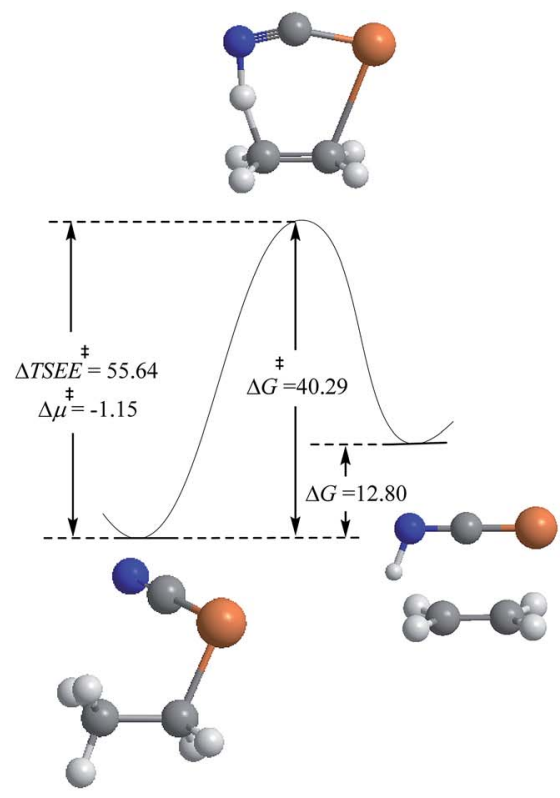

3-gauche

Fig. 2 MP2/6-311++G** calculated comparative potential energy profiles of the retro-ene decomposition reactions of compounds 1-3 in accordance with the Hammond-Leffler postulate. $\Delta G, \Delta G^{\ddagger}$, and $\Delta$ TSEE $^{\star}$ values are in $\mathrm{kcal} \mathrm{mol}^{-1} . \Delta \mu^{\ddagger}$ values are in Debye. 
Table $1 \mathrm{MP2} / 6-311++\mathrm{G}^{* *(a)}$ and G3MP2(b) calculated zero-point energies (ZPE, in Hartree), relative ZPE ( $\Delta$ ZPE in kcal mol $\left.{ }^{-1}\right)$, corrected electronic energies ( $E_{\mathrm{O}}$, in Hartree), $\Delta E_{\mathrm{O}}$, thermodynamic parameters $\left[\Delta H, \Delta G\right.$ (in kcal mol ${ }^{-1}$ )] and $\Delta S$ (in cal mol ${ }^{-1} \mathrm{~K}^{-1}$ ) at $25^{\circ} \mathrm{C}$ and 1 atm pressure for the gauche- and anti-conformations of compounds 1-3

\begin{tabular}{|c|c|c|c|c|c|c|c|c|c|c|}
\hline \multirow[b]{2}{*}{ Geometry } & \multicolumn{5}{|c|}{$\mathrm{MP} 2 / 6-311++\mathrm{G}^{* *}$} & \multicolumn{5}{|l|}{ G3MP2 } \\
\hline & $\Delta \mathrm{ZPE}$ & $\Delta E_{\mathrm{o}}$ & $\Delta H$ & $\Delta S$ & $\Delta G$ & $\Delta \mathrm{ZPE}$ & $\Delta E_{\mathrm{o}}$ & $\Delta H$ & $\Delta S$ & $\Delta G$ \\
\hline 1-gauche & 0.00 & 0.00 & 0.00 & 0.000 & 0.00 & $0.00^{b}$ & $0.00^{b}$ & $0.00^{b}$ & $0.000^{b}$ & $0.00^{b}$ \\
\hline 1-anti & -0.14 & $\begin{array}{l}0.09 \\
(0.05)^{a} \\
(-0.14)^{b} \\
(-0.11)^{c}\end{array}$ & 0.20 & 1.192 & $\begin{array}{l}-0.15 \\
(-0.16)^{c}\end{array}$ & $0.09^{b}$ & $0.05^{b}$ & $0.12^{b}$ & $0.371^{b}$ & $0.01^{b}$ \\
\hline 1-TS & -4.017 & 31.21 & 30.79 & -3.373 & $31.80^{a}$ & -4.733 & 31.27 & 31.10 & -1.951 & $31.68^{b}$ \\
\hline 2-gauche & 0.08 & 0.00 & 0.00 & $0.000^{a}$ & $0.00^{a}$ & $0.02^{b}$ & $0.00^{b}$ & $0.00^{b}$ & $0.000^{b}$ & $0.00^{b}$ \\
\hline 2-anti & 0.00 & $\begin{array}{l}1.12 \\
(1.06)^{a} \\
(1.02)^{b}\end{array}$ & 1.25 & $1.871^{a}$ & $0.69^{a}$ & $0.00^{b}$ & $0.86^{b}$ & $0.93^{b}$ & $0.672^{b}$ & $0.73^{b}$ \\
\hline & & & $\begin{array}{l}1.00 \pm 0.07^{d} \\
1.68 \pm 0.07^{e}\end{array}$ & & & & & & & \\
\hline 2-TS & -4.145 & 39.86 & 39.39 & -3.829 & $40.53^{a}$ & -4.580 & 40.538 & 40.40 & -1.307 & $40.79^{b}$ \\
\hline 3-gauche & $0.07^{a}$ & $0.00^{a}$ & $0.00^{a}$ & $0.000^{a}$ & $0.00^{a}$ & $0.02^{b}$ & $0.00^{b}$ & $0.00^{b}$ & $0.000^{b}$ & $0.00^{b}$ \\
\hline 3-anti & 0.00 & $\begin{array}{l}1.19^{a} \\
(1.07)^{a} \\
(1.36)^{b}\end{array}$ & $1.30^{a}$ & $1.480^{a}$ & $0.86^{a}$ & $0.00^{b}$ & $0.90^{b}$ & $0.96^{b}$ & $0.787^{b}$ & $0.72^{b}$ \\
\hline 3-TS & -4.046 & 39.58 & 39.09 & -4.064 & $40.29^{a}$ & -4.474 & 40.99 & 40.82 & -1.310 & $41.21^{b}$ \\
\hline
\end{tabular}

${ }^{a}$ From MP2, ref. 19. ${ }^{b}$ From MP4, ref. 19. ${ }^{c}$ From $\operatorname{CCSD}(\mathrm{T}) / 6-311+\mathrm{G}(2 \mathrm{~d}, 2 \mathrm{p}) / / \mathrm{QCISD} / 6-311+\mathrm{G}(\mathrm{d}, \mathrm{p})$, ref. $20 .{ }^{d}$ From infrared spectroscopy, ref. 26.

${ }^{e}$ From Raman spectroscopy, ref. 25.

also their corresponding retro-ene decomposition reactions (Fig. 2) at the MP2/6-311++G** level of theory. Based on our findings and also the published theoretical data in the literature,$^{\mathbf{2 0 , 2 1}}$ we found that the retro-ene decomposition reactions of compounds 1-3 proceed through pathways with lower activation barriers (with more stable transition states) and produce less stable products compared to their corresponding cyanate $\rightarrow$ isocyanate unimolecular isomerization reactions. Accordingly, the retro-ene decomposition reactions of compounds 1-3 could be kinetically controlled at lower temperatures. At higher temperatures, the cyanate $\rightarrow$ isocyanate unimolecular isomerization reactions of compounds 1-3 may proceed through pathways with greater activation barriers (with less stable transition states) and the major products are the thermodynamically more stable systems.

Fig. 1 shows that the barrier heights of the unimolecular cyanate $\rightarrow$ isocyanate unimolecular isomerization reactions increase significantly from compound 1 to compound 2, but decrease from compound 2 to compound 3 . It is worth noting that the unimolecular cyanate $\rightarrow$ isocyanate unimolecular isomerization reaction of compound $\mathbf{1}$ is evidently endothermic, but the corresponding endothermicity decreases drastically from compound $\mathbf{1}$ to compound 2 , while it does not change significantly from compound 2 to compound 3 .

The MP2/6-311++G** results showed that the retro-ene decomposition reaction barrier height increases drastically from compound 1 to compound 2, but it does not change significantly going from compound 2 to compound 3 (Fig. 2). It is worth noting that the retro-ene decomposition reaction of compound $\mathbf{1}$ is exothermic. On the contrary, the retro-ene decomposition reactions of compounds 2 and 3 are endothermic and the endothermicity increases from compound 2 to compound 3 (Table 1 and ESI-1†).

\section{Assessing the impacts of the hyperconjugative interactions on the conformational preferences and retro-ene decomposition reactions of compounds 1-3}

The contributions of the generalized anomeric effects associated with the hyperconjugative interactions (HCGAE) on the conformational preferences in compounds 1-3 were analyzed and the corresponding results are given in Table 2 . The NBO$\mathrm{MP} 2 / 6-311++\mathrm{G}^{* *}$ analysis showed that the $\mathrm{LP}_{2} \mathrm{X}_{3} \rightarrow \sigma_{\mathrm{C}_{4}-\mathrm{C}_{5}}^{*}[\mathrm{X}=$ $\mathrm{O}(1), \mathrm{S}(2)$, Se (3)] and $\sigma_{\mathrm{C}_{4}-\mathrm{H}_{7}} \rightarrow \sigma_{\mathrm{C}_{3}-\mathrm{C}_{2}}^{*}$ electron delocalizations have the greatest impact on the magnitudes of the total hyperconjugative anomeric effects ( $\mathrm{HCAE}_{\text {total }}$ ) of compounds 1-3. Seemingly, the $\mathrm{HCAE}_{\text {total }}$ values in compounds 1-3 are controlled by the $\mathrm{LP}_{2} \mathrm{X}_{3} \rightarrow \sigma_{\mathrm{C}_{4}-\mathrm{C}_{5}}^{*}$ and $\sigma_{\mathrm{C}_{4}-\mathrm{H}_{7}} \rightarrow \sigma_{\mathrm{C}_{3}-\mathrm{C}_{2}}^{*}$ electron delocalizations. Based on the results obtained, the HCGAE $\left(\mathrm{HCGAE}_{\text {anti }}-\mathrm{HCGAE}_{\text {gauche }}\right)$ values associated with the $\mathrm{LP}_{1} \mathrm{X}_{3} \rightarrow \sigma_{\mathrm{C}_{4}-\mathrm{C}_{5}}^{*}, \mathrm{LP}_{2} \mathrm{X}_{3} \rightarrow \sigma_{\mathrm{C}_{4}-\mathrm{C}_{5}}^{*}, \mathrm{LP}_{1} \mathrm{X}_{3} \rightarrow \sigma_{\mathrm{C}_{4}-\mathrm{H}_{6}}^{*}, \mathrm{LP}_{2} \mathrm{X}_{3} \rightarrow \sigma_{\mathrm{C}_{4}-\mathrm{H}_{7}}^{*}$, $\sigma_{\mathrm{C}_{4}-\mathrm{C}_{5}} \rightarrow \sigma_{\mathrm{X}_{3}-\mathrm{C}_{2}}^{*}, \sigma_{\mathrm{C}_{4}-\mathrm{H}_{7}} \rightarrow \sigma_{\mathrm{X}_{3}-\mathrm{C}_{2}}^{*}, \sigma_{\mathrm{X}_{3}-\mathrm{C}_{4}} \rightarrow \sigma_{\mathrm{C}_{2} \equiv \mathrm{N}_{1}}^{*}, \sigma_{\mathrm{X}_{3}-\mathrm{C}_{4}} \rightarrow$ $\pi_{\mathrm{C}_{2} \equiv \mathrm{N}_{1}}^{*}$, and $\sigma_{\mathrm{C}_{5}-\mathrm{H}_{8}} \rightarrow \sigma_{\mathrm{X}_{3}-\mathrm{C}_{4}}^{*}$ hyperconjugative interactions are in favor of the gauche-conformations of compounds 1-3 compared with their corresponding anti-conformations. It is worth noting that the $\mathrm{HCGAE}_{\text {total }}$ values decrease slightly from compound $\mathbf{1}$ to compound $\mathbf{3}$, revealing that the generalized anomeric effects associated with the hyperconjugative interactions are in favor of the gauche-conformations in compounds 13 but are not solely responsible for the variations of the gaucheconformations stabilities compared with their corresponding anti-conformations going from compound $\mathbf{1}$ to compound $\mathbf{3}$. 
Table 2 NBO-MP2/6-311++G** calculated hyperconjugative generalized anomeric effect (HCGAE, in kcal mol ${ }^{-1}$ ) associated with the hyperconjugative interactions and off-diagonal elements $\left(F_{i j}\right.$, in atomic unit) for the gauche- and anti-conformations of compounds $1-3$

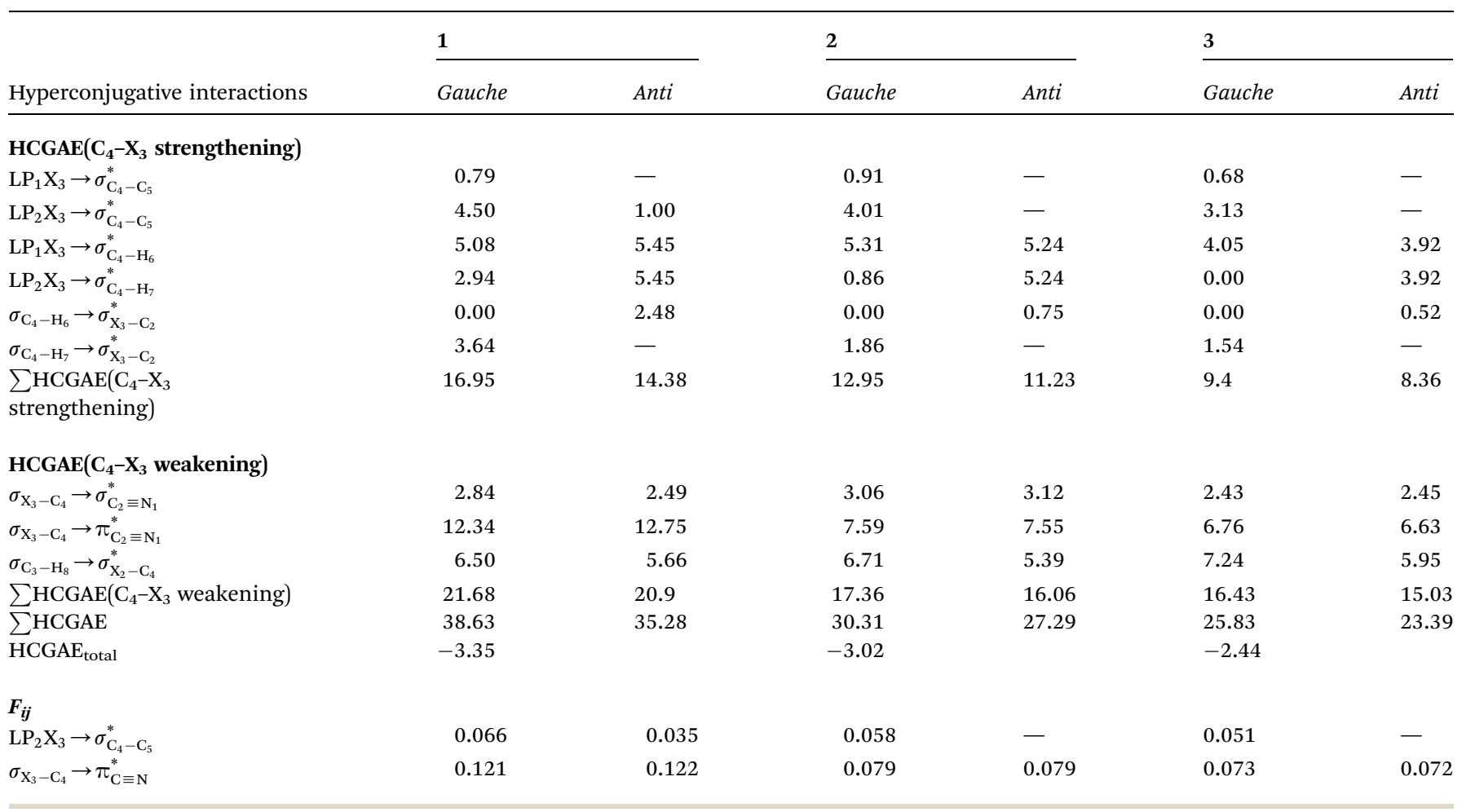

Therefore, the roles and contributions of other factors (e.g., the electrostatic model and steric effects) should be accounted for (Table 2).

In order to estimate quantitatively the impacts of the hyperconjugative interactions on the conformational preferences in compounds 1-3, we deleted the hyperconjugative interactions (in which the overlapping of their corresponding orbitals change with the rotations around the $\mathrm{X}_{3}-\mathrm{C}_{4}$ bonds: $\mathrm{LP}_{1} \mathrm{X}_{3} \rightarrow \sigma_{\mathrm{C}_{4}-\mathrm{C}_{5}}^{*}, \mathrm{LP}_{2} \mathrm{X}_{3} \rightarrow \sigma_{\mathrm{C}_{4}-\mathrm{C}_{5}}^{*}, \mathrm{LP}_{1} \mathrm{X}_{3} \rightarrow \sigma_{\mathrm{C}_{4}-\mathrm{H}_{6}}^{*}, \mathrm{LP}_{2} \mathrm{X}_{3} \rightarrow$ $\sigma_{\mathrm{C}_{4}-\mathrm{H}_{7}}^{*}, \sigma_{\mathrm{C}_{4}-\mathrm{C}_{5}} \rightarrow \sigma_{\mathrm{X}_{3}-\mathrm{C}_{2}}^{*}, \sigma_{\mathrm{C}_{4}-\mathrm{H}_{7}} \rightarrow \sigma_{\mathrm{X}_{3}-\mathrm{C}_{2}}^{*}, \sigma_{\mathrm{X}_{3}-\mathrm{C}_{4}}^{*} \rightarrow \sigma_{\mathrm{C}_{2} \equiv \mathrm{N}_{1}}^{*}, \sigma_{\mathrm{X}_{3}-\mathrm{C}_{4}}$ $\rightarrow \pi_{\mathrm{C}_{2} \equiv \mathrm{N}_{1}}^{*}$, and $\sigma_{\mathrm{C}_{5}-\mathrm{H}_{8}} \rightarrow \sigma_{\mathrm{X}_{3}-\mathrm{C}_{4}}^{*}$ electron delocalizations) from the Fock matrices of the gauche- and anti-conformations. Then, with rediagonalization and comparison of the current Fock matrices with their original forms, we found that the anticonformations of compounds 1-3 became more stable than their corresponding chiral gauche-conformations, revealing that the anomeric relationships in compounds 1-3 may have a hyperconjugative interactions origin (Table 3 ).

Since the $\mathrm{X}_{3}-\mathrm{C}_{4}[\mathrm{X}=\mathrm{O}(\mathbf{1}), \mathrm{S}(2)$, Se (3)] bonds break in the transition state structures of the retro-ene decomposition reactions, we may expect that the retro-ene decomposition reaction barrier heights may decrease going from compound 1 to compound 3. The results obtained in this work, however, do not confirm this expectation. Based on the results obtained at the MP2/6-311++G** level of theory, the retro-ene decomposition reaction barrier height increases drastically from compound 1 to compound 2, but does not change significantly going from compound 2 to compound 3 (Table 1, ESI-1 and ESI- $2 \dagger$ ).

\section{Orbital amplitudes (electron densities) associated with the hyperconjugative interactions}

The impacts of the hyperconjugative generalized anomeric effect (HCGAE) on the retro-ene decomposition reactions barrier heights of compounds 1-3 were investigated. Seemingly, the $\mathrm{LP}_{2} \mathrm{X}_{3} \rightarrow \sigma_{\mathrm{C}_{4}-\mathrm{C}_{5}}^{*}$ and $\sigma_{\mathrm{X}_{3}-\mathrm{C}_{4}} \rightarrow \pi_{\mathrm{C}_{2} \equiv \mathrm{N}_{1}}^{*}$ electron delocalizations have the greatest impact on the easiness of the breaking of the $\mathrm{X}_{3}-\mathrm{C}_{4}$ bonds, thus we analyzed their corresponding donoracceptor orbital amplitude profiles (or electron densities) (Fig. 3 and 4). Fig. 3 shows that the mixings of the lobes of the donor $\mathrm{LP}_{2} \mathrm{X}_{3}$ nonbonding and acceptor $\sigma_{\mathrm{C}_{4}-\mathrm{C}_{5}}^{*}$ antibonding orbitals decrease from the gauche-conformations of compound $\mathbf{1}$ to compound 3, revealing that the variations of the off-diagonal elements control the variations of the mixing of the doubly occupied orbitals of $\mathrm{LP}_{2} \mathrm{M}_{3}[\mathrm{X}=\mathrm{O}(\mathbf{1}), \mathrm{S}(2)$, Se (3)] with the adjacent unoccupied orbitals of the $\mathrm{CH}_{2}-\mathrm{CH}_{3}$ bonds $\left(\mathrm{LP}_{2} \mathrm{M}_{3}+\sigma_{\mathrm{CH}_{2}-\mathrm{CH}_{3}}^{*}\right)$. A same trend was observed for mixing of the lobes of the donor $\sigma_{\mathrm{X}_{3}-\mathrm{C}_{4}}$ bonding and acceptor $\pi_{\mathrm{C}_{2} \equiv \mathrm{N}_{1}}^{*}$ antibonding orbitals, which is in accordance with the Mulliken (or Wolfberg-Helmholtz) approximation..$^{47,48}$ Based on the Mulliken (or Wolfberg-Helmholtz) approximation, the desirable orbital overlapping between the donor and acceptor orbitals are reachable by substantial adjustments of their offdiagonal terms.

\section{HCGAE $_{\text {total }}$ decomposition into the $\mathrm{X}_{3}-\mathrm{C}_{4}$ bonds strengthening and weakening components}

It is worth noting that $\mathrm{HCGAE}_{\text {total }}$ could be decomposed into two components: the first component has an impact on the 
Table $3 \mathrm{HF} / 6-311++\mathrm{G} * * / / \mathrm{MP} 2 / 6-311++\mathrm{G}^{* *}$ calculated total SCF energies, energies of deletions associated with the deletion of $\mathrm{LP}_{1} \mathrm{X}_{3} \rightarrow \sigma_{\mathrm{C}_{4}-\mathrm{C}_{5}}^{*}, \mathrm{LP}_{2} \mathrm{X}_{3} \rightarrow \sigma_{\mathrm{C}_{4}-\mathrm{C}_{5}}^{*}, \mathrm{LP}_{1} \mathrm{X}_{3} \rightarrow \sigma_{\mathrm{C}_{4}-\mathrm{H}_{6}}^{*}, \mathrm{LP}_{2} \mathrm{X}_{3} \rightarrow \sigma_{\mathrm{C}_{4}-\mathrm{H}_{7}}^{*}, \sigma_{\mathrm{C}_{4}-\mathrm{C}_{5}} \rightarrow \sigma_{\mathrm{X}_{3}-\mathrm{C}_{2}}^{*}, \sigma_{\mathrm{C}_{4}-\mathrm{H}_{7}} \rightarrow \sigma_{\mathrm{X}_{3}-\mathrm{C}_{2}}^{*}, \sigma_{\mathrm{X}_{3}-\mathrm{C}_{4}} \rightarrow \sigma_{\mathrm{C}_{2}}^{*} \equiv \mathrm{N}_{1}, \sigma_{\mathrm{X}_{3}-\mathrm{C}_{4}} \rightarrow \pi_{\mathrm{C}_{2}}^{*} \equiv \mathrm{N}_{1}$, and $\sigma_{\mathrm{C}_{5}-\mathrm{H}_{8}} \rightarrow$ $\sigma_{\mathrm{X}_{3}-\mathrm{C}_{4}}^{*}$ electron delocalizations and their corresponding energy changes (in a.u.) in the gauche- and anti-conformations of compounds $1-3$

\begin{tabular}{|c|c|c|c|c|c|c|}
\hline \multirow[b]{2}{*}{ Geometries } & \multicolumn{2}{|l|}{1} & \multicolumn{2}{|l|}{2} & \multicolumn{2}{|l|}{3} \\
\hline & Gauche & Anti & Gauche & Anti & Gauche & Anti \\
\hline Energies of deletions & -245.801561 & -245.807529571 & -568.479413418 & -568.483811670 & -2570.745744656 & -2570.749046882 \\
\hline Energy changes (EC) & $0.051955(32.60)^{a}$ & $0.047082(29.54)^{a}$ & $0.041860(26.27)^{a}$ & $0.037274(23.39)^{a}$ & $0.035811(22.47)^{a}$ & $0.032271(20.25)^{a}$ \\
\hline$\Delta\left(\mathrm{EC}_{\text {gauche }}-\mathrm{EC}_{\text {anti }}\right)$ & $3.06^{a}$ & & $2.88^{a}$ & & $2.22^{a}$ & \\
\hline
\end{tabular}

${ }^{a}$ Values are in $\mathrm{kcal} \mathrm{mol}^{-1}$.

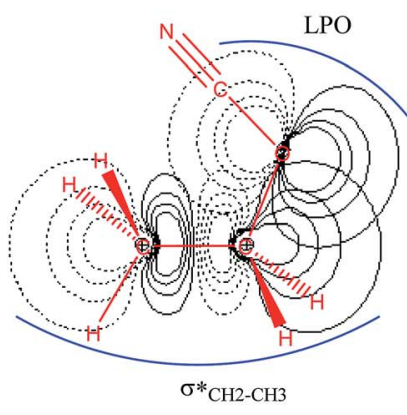

$\mathrm{LP}_{2} \mathrm{O}_{3} \rightarrow \sigma^{*}{ }_{\mathrm{C} 4-\mathrm{C} 5}, \mathrm{E}_{2}=4.50$

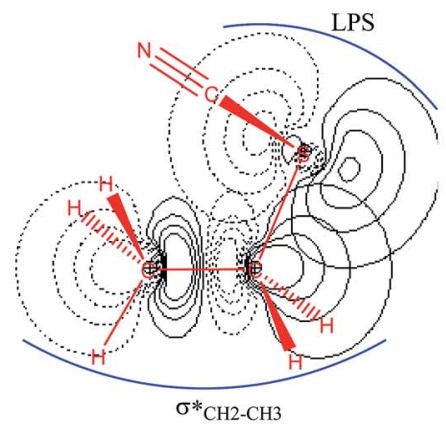

$\mathrm{LP}_{2} \mathrm{~S}_{3} \rightarrow \sigma^{*}{ }_{\mathrm{C} 4-\mathrm{C} 5}, \mathrm{E}_{2}=4.01$

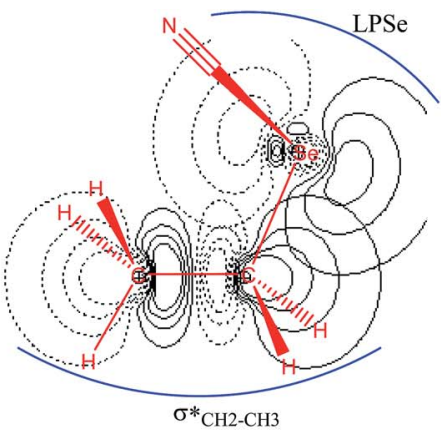

$\mathrm{LP}_{2} \mathrm{Se}_{3} \rightarrow \sigma^{*}{ }_{\mathrm{C} 4-\mathrm{C} 5}, \mathrm{E}_{2}=3.13$

Fig. 3 Calculated profiles of the orbital amplitudes (electron densities) for the $L P_{2} X_{3} \rightarrow \sigma_{C_{4}-C_{5}}^{*}[X=O$ (1), $S$ (2), Se (3)] negative hyperconjugative interactions that shorten the $X_{3}-C_{4}$ bonds in the gauche-conformations of compounds $1-3$. $E_{2}$ values are in kcal mol ${ }^{-1}$.

decrease of the $\mathrm{X}_{3}-\mathrm{C}_{4}$ bond orders $\left[\operatorname{HCGAE}\left(\mathrm{X}_{3}-\mathrm{C}_{4}\right.\right.$ strengthening)], while the second one has an opposite impact $\left[\operatorname{HCGAE}\left(\mathrm{X}_{3}-\mathrm{C}_{4}\right.\right.$ weakening)] (see Table 2). The calculated $\operatorname{HCGAE}\left(\mathrm{X}_{3}-\mathrm{C}_{4}\right.$ strengthening) values associated with the $\mathrm{LP}_{1} \mathrm{X}_{3} \rightarrow \sigma_{\mathrm{C}_{4}-\mathrm{C}_{5}}^{*}, \mathrm{LP}_{2} \mathrm{X}_{3} \rightarrow \sigma_{\mathrm{C}_{4}-\mathrm{C}_{5}}^{*}, \mathrm{LP}_{1} \mathrm{X}_{3} \rightarrow \sigma_{\mathrm{C}_{4}-\mathrm{H}_{6}}^{*}, \mathrm{LP}_{2} \mathrm{X}_{3} \rightarrow$ $\sigma_{\mathrm{C}_{4}-\mathrm{H}_{7}}^{*}, \sigma_{\mathrm{C}_{4}-\mathrm{C}_{5}}^{*} \rightarrow \sigma_{\mathrm{X}_{3}-\mathrm{C}_{2}}^{*}$, and $\sigma_{\mathrm{C}_{4}-\mathrm{H}_{7}} \rightarrow \sigma_{\mathrm{X}_{3}-\mathrm{C}_{2}}^{*}$ electron delocalizations and the $\operatorname{HCGAE}\left(\mathrm{X}_{3}-\mathrm{C}_{4}\right.$ weakening) values associated with the $\sigma_{\mathrm{X}_{3}-\mathrm{C}_{4}} \rightarrow \sigma_{\mathrm{C}_{2} \equiv \mathrm{N}_{1}}^{*}, \sigma_{\mathrm{X}_{3}-\mathrm{C}_{4}} \rightarrow \pi_{\mathrm{C}_{2} \equiv \mathrm{N}_{1}}^{*}$, and $\sigma_{\mathrm{C}_{5}-\mathrm{H}_{8}} \rightarrow$ $\sigma_{\mathrm{X}_{3}-\mathrm{C}_{4}}^{*}$ hyperconjugative interactions decrease from compound
1 to compound 3 , while their differences $\left(\Delta\left[\operatorname{HCGAE}\left(\mathrm{X}_{3}-\mathrm{C}_{4}\right.\right.\right.$ weakening) - $\operatorname{HCGAE}\left(\mathrm{X}_{3}-\mathrm{C}_{4}\right.$ strengthening $\left.\left.)\right]\right)$ increase significantly from compound $\mathbf{1}$ to compound 2 , but decrease slightly from compound 2 to compound 3. Surprisingly, the variations of the $\Delta\left[\operatorname{HCGAE}\left(\mathrm{X}_{3}-\mathrm{C}_{4}\right.\right.$ weakening $)-\operatorname{HCGAE}\left(\mathrm{X}_{3}-\mathrm{C}_{4}\right.$ strengthening)] parameters justifies the variations of the retro-ene decomposition reactions barrier heights going from compound 1 to compound 3 (Table 2 and Fig. 2).
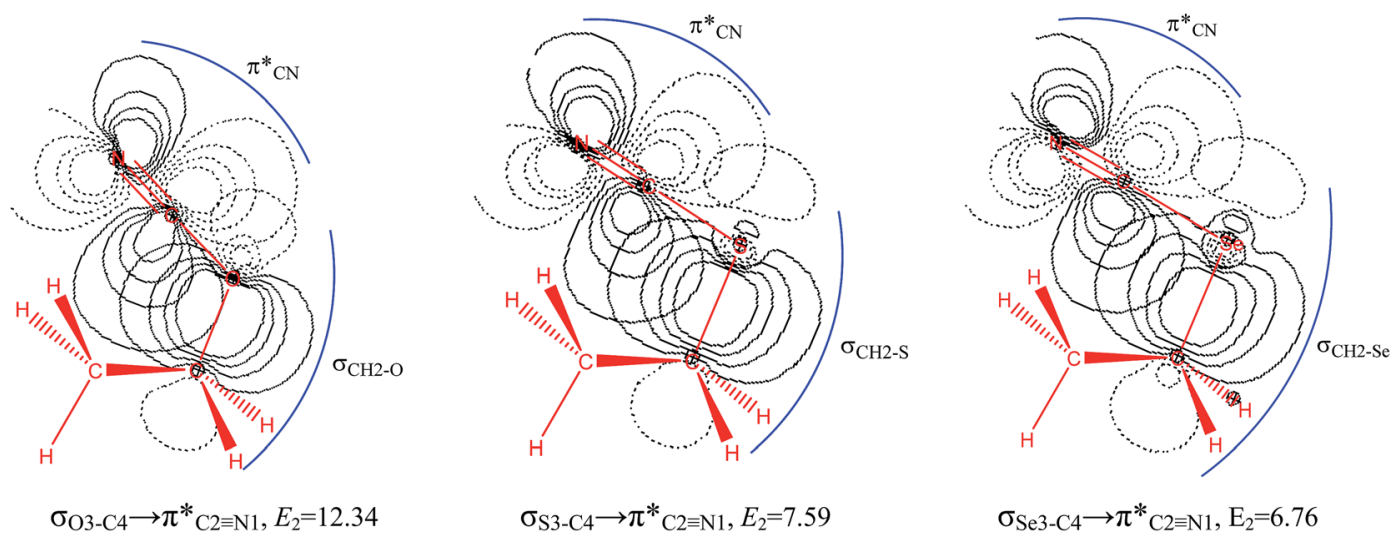

Fig. 4 Calculated profiles of the orbital amplitudes (electron densities) for the $\sigma_{X_{3}-C_{4}} \rightarrow \pi_{C_{2} \equiv N_{1}}^{*}[X=O$ (1), S (2), Se (3)] hyperconjugative interactions that lengthen the $\mathrm{X}_{3}-\mathrm{C}_{4}$ bonds in the gauche-conformations of compounds $1-3$. $E_{2}$ values are in kcal mol ${ }^{-1}$. 
5. Retro-ene decomposition reactions of compounds 1-3 in connection with the Hammond-Leffler postulate

The MP2/6-311 $+\mathrm{G}^{* *}$ results showed that the retro-ene decomposition reaction of compound $\mathbf{1}$ is exothermic and its transition state structure more closely resembles the gaucheconformation (with an early transition state). On the contrary, the retro-ene decomposition reactions of compounds 2 and 3 are endothermic and their transition state structures more closely resemble their corresponding products (with late transition states). In order to assess the validity of the HammondLeffler postulate for the retro-ene reactions of compounds 1-3, we examined the total natural resonance theory (NRT) bond orders (natural bond orders, nbo) of the reactants, the transition state structures, and the products of the retro-ene reactions of compounds 1-3 (Table 4). The examinations of the bond orders of the transition state structures revealed that the bond orders of the retro-ene decomposition reaction of compound 1 more resemble the gauche-conformation (Fig. 5), which is in agreement with the Hammond-Leffler postulate. Interestingly, the bond orders of the six-membered cyclic transition state structures of the retro-ene decomposition reactions of compounds 2 and 3 are closer to their corresponding products.

Although the $\mathrm{C}-\mathrm{X}(\mathrm{X}=\mathrm{O}, \mathrm{S}, \mathrm{Se})$ bond dissociation energy decreases when going from $\mathrm{C}-\mathrm{O}$ to $\mathrm{C}-\mathrm{Se}$ bonds, the barrier heights of the decomposition and isomerization reactions of ethyl selenocyanate (3) are significantly greater than those in ethyl cyanate (1) and also are close to the corresponding values for ethyl thiocyanate (2). It is worth noting that six bonds $\left(\mathrm{N}_{1} \cdots \mathrm{C}_{2}, \mathrm{C}_{2} \cdots \mathrm{X}_{3}, \mathrm{X}_{3} \cdots \mathrm{C}_{4}, \mathrm{C}_{4} \cdots \mathrm{C}_{5}, \mathrm{C}_{5} \cdots \mathrm{H}_{9}, \mathrm{H}_{9} \cdots \mathrm{N}_{1}\right)$ are involved in the transition state structures of the retro-ene decomposition reactions of compounds $\mathbf{1}-\mathbf{3}$. The $\mathrm{C}_{5} \cdots \mathrm{H}_{9}$ bond in the transition state structure of the retro-ene decomposition reaction of compound $\mathbf{1}$ has a significant covalent character, while there is no considerable bond order for the $\mathrm{H}_{9} \cdots \mathrm{N}_{1}$ bonds. Importantly, the bond orders of the $\mathrm{C}_{5} \cdots \mathrm{H}_{9}$ bonds decrease going from the transition state structures of compound 1 to compound 3, while the bond orders of the $\mathrm{H}_{9} \cdots \mathrm{N}_{1}$ bonds increase inversely. Also, the bond orders of the $\mathrm{C}-\mathrm{C}$ bonds in the transitions state structures increase significantly from the transition state structures of compound $\mathbf{1}$ to compound $\mathbf{3}$. It can thus be concluded that the variations of the barrier heights of the retroene decomposition reactions of compounds 1-3 could not be controlled only by the $\mathrm{X}_{3}-\mathrm{C}_{4}(\mathrm{X}=\mathrm{O}, \mathrm{S}, \mathrm{Se})$ bonds and therefore the contributions of the other bonds involved in the retro-ene decomposition reactions and their corresponding angle strains should be considered.

It is worth noting that the variations of the bond orders of the transition state structures of the retro-ene reactions of compounds 1-3 are reflected in their structural parameters. Based on the results obtained at the MP2/6-311++G** level of theory, the $\mathrm{C}-\mathrm{C}$ bond lengths and the $\mathrm{H} \cdots \mathrm{N}$ distances decrease going from the transition state structures of the retro-ene reactions of compound 1 to compound 3 (Fig. 6). As the $\mathrm{C}-\mathrm{C}$ bond lengths and the $\mathrm{H} \cdots \mathrm{N}$ distances decrease, the $\mathrm{C}-\mathrm{H}$ bond lengths increase inversely, leading to the formation of the late transition structures that resemble their corresponding products (Fig. 1 and 2). Accordingly, the variations of the bond lengths in the transition state structures of the retro-ene decomposition reactions of compounds 1-3 are in accordance with the Hammond-Leffler postulate (Table ESI- $3 \dagger$ ).

\section{Exploring the impacts of the attractive electrostatic interactions between two adjacent atoms on the retro-ene decomposition reactions of compounds 1-3}

In order to assess the impacts of the attractive electrostatic interactions on the retro-ene decomposition reactions of

Table 4 NBO-MP2/6-311++G** calculated total natural resonance theory (NRT) bond orders (natural bond orders, nbo), relative variation of the bond orders for every bond $\left(\delta B_{i}\right)$, average values of $\delta B_{i}\left(\delta B_{\text {av }}\right)$ for the ground states, transition states, and products of the decomposition reactions of compounds 1-3 [X = O (1), S (2), Se (3)] and also their corresponding asynchronicity (Asy) and synchronicity values

\begin{tabular}{|c|c|c|c|c|c|c|c|c|c|}
\hline & \multicolumn{3}{|l|}{1} & \multicolumn{3}{|l|}{2} & \multicolumn{3}{|l|}{3} \\
\hline & Gauche & TS & $\mathrm{P}$ & Gauche & TS & $\mathrm{P}$ & Gauche & TS & $\mathrm{P}$ \\
\hline \multicolumn{10}{|l|}{ WBI } \\
\hline $\mathrm{N}_{1}-\mathrm{C}_{2}$ & 2.9248 & 2.4089 & 2.0061 & 2.9301 & 2.3596 & 2.0929 & 2.9447 & 2.4249 & 2.1856 \\
\hline $\mathrm{C}_{2}-\mathrm{X}_{3}$ & 1.0710 & 1.5524 & 1.9861 & 1.0652 & 1.5257 & 1.8968 & 1.0501 & 1.4746 & 1.7951 \\
\hline $\mathrm{X}_{3}-\mathrm{C}_{4}$ & 0.9897 & 0.5908 & 0.0000 & 0.9906 & 0.3736 & 0.0000 & 0.9852 & 0.3230 & 0.0000 \\
\hline $\mathrm{C}_{4}-\mathrm{C}_{5}$ & 1.0200 & 1.1547 & 2.0154 & 1.0234 & 1.4747 & 2.0154 & 1.0255 & 1.5254 & 2.0154 \\
\hline $\mathrm{C}_{5}-\mathrm{H}_{9}$ & 0.9910 & 0.8173 & 0.0000 & 0.9908 & 0.4308 & 0.0000 & 0.9905 & 0.3839 & 0.0000 \\
\hline $\mathrm{N}_{1}-\mathrm{H}_{9}$ & 0.0000 & 0.0355 & 0.9731 & 0.0000 & 0.3876 & 0.9662 & 0.0000 & 0.4481 & 0.9606 \\
\hline \multicolumn{10}{|l|}{$\delta \mathbf{B}_{i}$} \\
\hline$\delta B_{\mathrm{N}_{1}-\mathrm{C}_{2}}$ & & 0.5614 & & & 0.6814 & & & 0.6848 & \\
\hline$\delta B_{\mathrm{C}_{2}-\mathrm{X}_{3}}$ & & 0.5261 & & & 0.5538 & & & 0.5698 & \\
\hline$\delta B_{\mathrm{X}_{3}-\mathrm{C}_{4}}$ & & 0.4031 & & & 0.6229 & & & 0.6721 & \\
\hline$\delta B_{\mathrm{C}_{4}-\mathrm{C}_{5}}$ & & 0.1353 & & & 0.4549 & & & 0.5050 & \\
\hline$\delta B_{\mathrm{C}_{5}-\mathrm{H}_{9}}$ & & 0.1753 & & & 0.5652 & & & 0.6124 & \\
\hline$\delta B_{\mathrm{N}_{1}-\mathrm{H}_{9}}$ & & 0.0365 & & & 0.4012 & & & 0.4665 & \\
\hline$\delta B_{\mathrm{av}}$ & & 0.3063 & & & 0.5466 & & & 0.5851 & \\
\hline ASy & & 0.3733 & & & 0.0018 & & & 0.0736 & \\
\hline Sy & & 0.6267 & & & 0.9816 & & & 0.9264 & \\
\hline
\end{tabular}




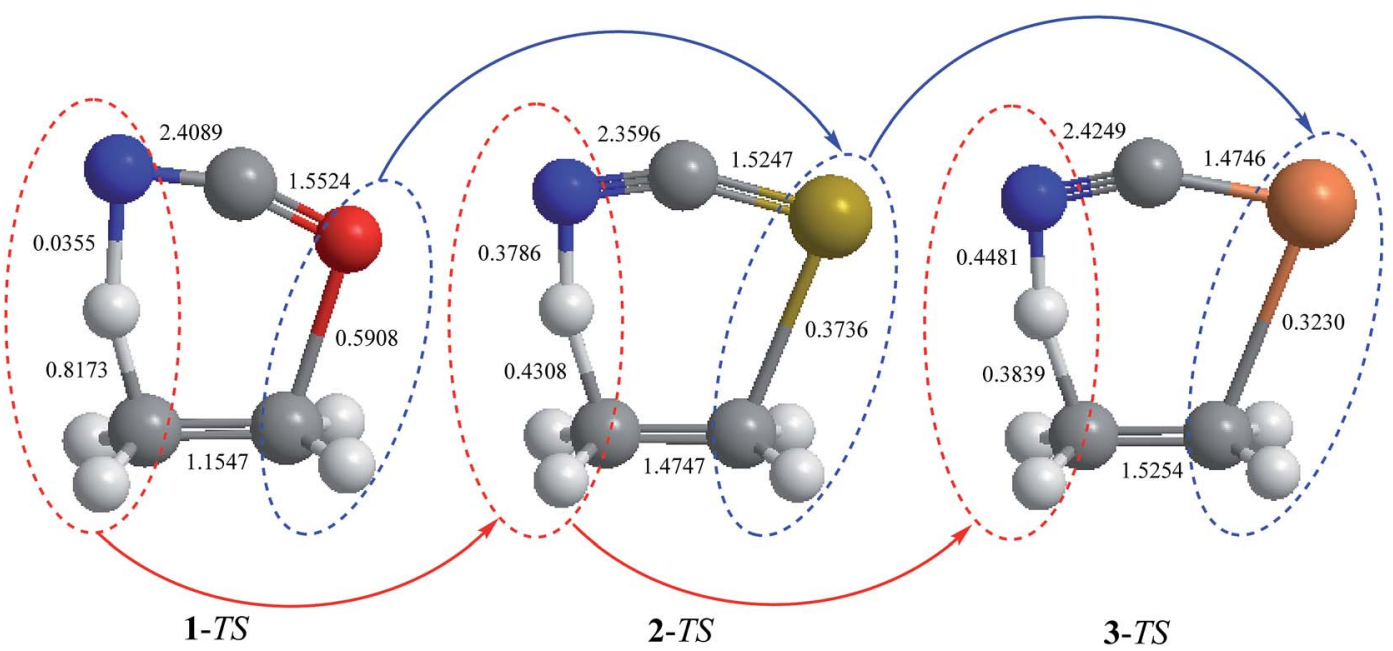

Fig. $5 \mathrm{MP2} / 6-311++\mathrm{G} * *$ calculated total natural resonance theory (NRT) bond orders (natural bond orders, nbo) of the transition state structures of the retro-ene decomposition reactions of compounds $1-3$.

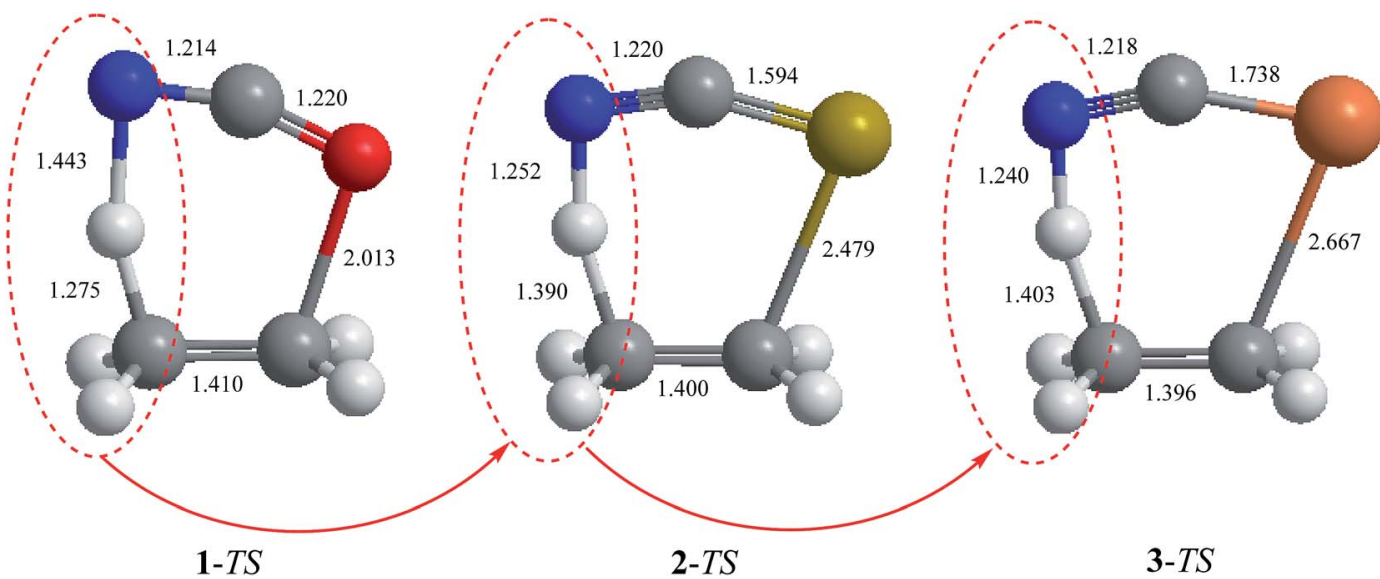

Fig. $6 \mathrm{MP} 2 / 6-311++\mathrm{G}^{* *}$ calculated structural parameters (bond lengths, $\AA$ ) of the transition state structures of the retro-ene decomposition reactions of compounds $1-3$.

compounds 1-3, we examined the natural atomic charges (NAC) of the $\mathrm{X}_{3}$ and $\mathrm{C}_{4}$ atoms (Scheme 1). The results obtained showed that the natural atomic charge of the $\mathrm{O}$ atom is negative, while the $\mathrm{S}$ and Se atoms possess positive charges.

Effectively, the calculated natural atomic charge differences between the $\mathrm{X}_{3}$ and $\mathrm{C}_{4}$ atoms in the gauche-conformations $(\Delta$ $\left.\left[\mathrm{NAC}\left(\mathrm{X}_{3}\right)-\mathrm{NAC}\left(\mathrm{C}_{4}\right)\right]\right)$ increase from compound 1 to compound 3 (Table 5). The smaller $\Delta\left[\mathrm{NAC}\left(\mathrm{X}_{3}\right)-\mathrm{NAC}\left(\mathrm{C}_{4}\right)\right]$ parameter in compound $\mathbf{1}$ compared to those in compounds $\mathbf{2}$ and $\mathbf{3}$ leads to an early transition state (smaller $\delta B_{\text {av }}$ value). The greater attractive electrostatic interactions between the two adjacent $\mathrm{S}_{3}-\mathrm{C}_{4}$ and $\mathrm{Se}_{3}-\mathrm{C}_{4}$ atoms in compounds 2 and 3, respectively, (greater $\Delta\left[\mathrm{NAC}\left(\mathrm{X}_{3}\right)-\mathrm{NAC}\left(\mathrm{C}_{4}\right)\right]$ parameters) lead to the relatively late transition states (greater $\delta B_{\mathrm{av}}$ values) together with the increased overall synchronicity in the retro-ene decomposition reactions of compounds 2 and 3 . This fact could also be rationalized by the smaller $\sigma_{\mathrm{S}_{3}-\mathrm{C}_{4}} \rightarrow \pi_{\mathrm{C} \equiv \mathrm{N}}^{*}$ and $\sigma_{\mathrm{Se}_{3}-\mathrm{C}_{4}} \rightarrow \pi_{\mathrm{C} \equiv \mathrm{N}}^{*}$ electron delocalizations in the gauche-conformations of compounds 2 and 3 compared with that in compound 1 . Note that the greater $\sigma_{\mathrm{O}_{3}-\mathrm{C}_{4}} \rightarrow \pi_{\mathrm{C} \equiv \mathrm{N}}^{*}$ electron delocalization in the gaucheconformation of compound 1 facilitates more $\mathrm{O}_{3}-\mathrm{C}_{4}$ bond breaking in the retro-ene decomposition reaction of compound 1 compared with the smaller $\sigma_{\mathrm{X}_{3}-\mathrm{C}_{4}} \rightarrow \pi_{\mathrm{C} \equiv \mathrm{N}}^{*}$ electron delocalizations in compounds 2 and 3 (Table 2).

\section{Assessing the synchronicities and advancements of the transition states $\left(\delta B_{\mathrm{av}}\right)$ of the retro-ene decomposition reactions of compounds 1-3}

To gain further insights into the nature and mechanisms of the retro-ene decomposition reactions of compounds 1-3 and the applicability of the Hammond-Leffler postulate in these reactions, we examined their synchronicity indices by calculating the bond orders [total natural resonance theory (NRT) bond orders (natural bond orders, nbo)] of the gauche, transition state, and product structures. ${ }^{75-78}$

The synchronous or asynchronous nature of the mechanisms of the retro-ene decomposition reactions of compounds 
Table 5 MP2(FC)/6-311++G(d,p) calculated dipole moments ( $\mu$, in Debye) and total steric exchange energies for the gauche- and anticonformations and also for the transition state structures of the decomposition reactions of the gauche-conformations of compounds $1-3$. Natural atomic charges (NAC) are given for the gauche- and anti-conformations

\begin{tabular}{|c|c|c|c|c|c|c|c|c|c|}
\hline Compound & 1 & & & 2 & & & 3 & & \\
\hline Geometry & Gauche & Anti & TS & Gauche & Anti & TS & Gauche & Anti & TS \\
\hline$\mu$ & $\begin{array}{l}5.05 \\
(4.92)^{d}(4.60)^{e} \\
(4.59)^{f}\end{array}$ & $\begin{array}{l}5.24 \\
(4.72 \pm 0.33)^{a} \\
(5.13)^{d}(5.17)^{e} \\
(4.68)^{f}\end{array}$ & 4.63 & $\begin{array}{l}4.52 \\
(4.01 \pm 0.12)^{b} \\
(3.98)^{f}\end{array}$ & $\begin{array}{l}4.84 \\
(4.27)^{f}\end{array}$ & 3.51 & $\begin{array}{l}4.71 \\
(4.47 \pm 0.10)^{c} \\
(4.13)^{f}\end{array}$ & $\begin{array}{l}5.06 \\
(4.46)^{f}\end{array}$ & 3.56 \\
\hline$\Delta\left(\mu_{\text {anti }}-\mu_{\text {gauche }}\right)$ & 0.19 & & & 0.32 & & & 0.35 & & \\
\hline$\Delta\left(\mu_{\mathrm{TS}}-\mu_{\text {gauche }}\right)$ & & -0.42 & & & -1.01 & & & -1.15 & \\
\hline \multicolumn{10}{|l|}{ NAC } \\
\hline $\mathrm{X}_{3}$ & -0.60116 & -0.60663 & & 0.28657 & 0.28134 & & 0.40735 & 0.40180 & \\
\hline $\mathrm{C}_{4}$ & 0.07274 & 0.07204 & & -0.43066 & -0.42671 & & -0.48241 & -0.47864 & \\
\hline $\mathrm{N}_{1}$ & -0.49298 & -0.48980 & & -0.36828 & -0.36510 & & -0.37473 & -0.37081 & \\
\hline
\end{tabular}

${ }^{a}$ From rotational spectrum, ref. 18. ${ }^{b}$ From microwave spectrum, ref. 23. ${ }^{c}$ From microwave spectrum, ref. 27. ${ }^{d}$ From B3LYP/6-311+G(2d,2p), ref. 20.

${ }^{e}$ From QCISD(full)/6-311+G(d,p), ref. 20. ${ }^{f}$ From MP2 with a triple- $\xi$ basis set augmented with polarization and diffusion function, ref. 19.

1-3 were also considered by the synchronicity, Sy, as calculated from eqn (2):

$$
\text { Sy }=1-\text { ASy }
$$

where ASy is the asynchronicity (eqn (3)):

$$
\mathrm{ASy}=\left(\frac{1}{2 n-2}\right) \sum_{i=1}^{n} \frac{\left|\delta B_{i}-\delta B_{\mathrm{av}}\right|}{\delta B_{\mathrm{av}}}
$$

where $n$ is the number of bonds involved in the reaction and $\delta B_{i}$ is the relative variation of the bond index for every bond (eqn (4)) involved in the transition state (TS) structure in a chemical reaction:

$$
\delta B_{i}=\frac{B_{i}^{\mathrm{TS}}-B_{i}^{\mathrm{R}}}{B_{i}^{\mathrm{P}}-B_{i}^{\mathrm{R}}}
$$

From the calculated $\delta B_{i}$ values, we can measure the degree of advancement of the transition state structures along the reaction paths. $\delta B_{\mathrm{av}}$ is the average value (eqn (5)) and is defined as:

$$
\delta B_{\mathrm{av}}=\frac{1}{n} \sum_{i=1}^{n} \delta B_{i}
$$

The calculated total natural resonance theory (NRT) bond orders (natural bond orders, nbo), $\delta B_{i}, \delta B_{\mathrm{av}}$, ASy, and Sy values are given in Table 4. A low synchronicity was found for the retroene decomposition reaction of compound $\mathbf{1}$ compared with those in compound 2 and compound 3 . This fact could be justified by the bond orders of the $\mathrm{C}_{5} \cdots \mathrm{H}_{9} \cdots \mathrm{N}_{1}$ moiety in the transition state structure of compound 1 (Fig. 6). The examination of the bond orders of the $\mathrm{C}_{5} \cdots \mathrm{H}_{9} \cdots \mathrm{N}_{1}$ moiety in the transition state structure of compound 1 revealed that the $\mathrm{C}_{5} \cdots$ $\mathrm{H}_{9}$ bond had a significantly covalent character, while there was no considerable bond order for the $\mathrm{H}_{9} \cdots \mathrm{N}_{1}$ bond. This fact may lead to an early transition state structure. Contrary to compound 1, we found high synchronicity indices for the retroene decomposition reactions of compounds 2 and 3. Importantly, the decrease of the $\mathrm{C}_{5} \cdots \mathrm{H}_{9}$ bond orders and also the increase of the $\mathrm{H}_{9} \cdots \mathrm{N}_{1}$ bond orders in the $\mathrm{C}_{5} \cdots \mathrm{H}_{9} \cdots \mathrm{N}_{1}$ moieties of the transition state structures of compounds 2 and 3 compared with that in compound $\mathbf{1}$ led to their greater synchronicity indices. Despite the low synchronicity found for the retro-ene decomposition reaction of compound $\mathbf{1}$, the intrinsic reaction coordinate (IRC) analysis asserted the onestep nature of this reaction.

\section{Pauli exchange-type repulsions}

Natural steric analysis, which states that steric exchange repulsion is the energy difference due to orbital orthogonalization, can be used to express the well-established physical picture of steric repulsions. ${ }^{4-53}$ All occupied orbitals effects are included in the Pauli exchange-type repulsion (or steric exchange energy) and therefore it typically contains contributions from covalent (intrabond) groups.

NBO-MP2/6-311++G** analysis was used to calculate the steric repulsion contributions in the anti- and gauche-conformations and also in the transition state structures of the retroene reactions of 1-3. Based on the results obtained, Pauli exchange-type repulsion of the anti-conformation of compound 1 was found to be greater than that in its gauche-conformation, thus favoring the gauche-conformation. Contrary to the trend observed for compound 1, the exchange components of the gauche-conformations of compounds $\mathbf{2}$ and $\mathbf{3}$ were greater than those in their anti-conformations, thus favoring their corresponding anti-conformations. Accordingly, the exchange component tends to increase the anti-conformation preference compared to its gauche-conformation when going from compound 1 to compound 3. Based on the results obtained, the 
calculated total steric exchange energy differences between the anti- and gauche-conformations $\left[\Delta\left(\mathrm{TSEE}_{\text {anti }}-\mathrm{TSEE}_{\text {gauche }}\right)\right]$ decrease going from compound 1 to compound 3. Accordingly, the conformational preferences for the exchange component does not justify solely the conformational preferences in compounds 1-3 (Table 5).

It is worth noting that the Pauli exchange component values of the transition state structures of the retro-ene decomposition reactions of compounds 1-3 are greater than those in their corresponding anti- and gauche-conformations. Most importantly, the calculated total exchange energy differences between the transition state structures of the retro-ene decomposition reactions of compounds 1-3 correlate well with their corresponding Gibbs free energy differences, revealing that the variations of the exchange component have a significant impact on the barrier heights of these reactions (Fig. 2).

\section{Impact of the electrostatic model associated with the dipole-dipole interactions on the conformational preferences and the retro-ene decomposition reactions of compounds 1-3}

In the conformations or configurations of a molecule with larger dipole moments $(\mu)$, a larger polarizability may result from the local dipole moments repulsive interactions, therefore, it is acceptable that a conformation or configuration of a molecule with the largest resultant dipole moment (in the gas phase or in the nonpolar media) $)^{35}$ may possess the largest electrostatic energy compared to its structural isomers with smaller diploe moments.

The calculated dipole moments for the gauche- and anticonformations of compounds 1-3 and the transition state structures of their corresponding retro-ene decomposition reactions are given in Table 5. Based on the results obtained, the dipole moments of the gauche-conformations of compounds 13 are smaller than those in their corresponding anti-conformations, revealing that the electrostatic model associated with the dipole-dipole interaction is in favor of the gauche-conformations of compounds 1-3. It is worth noting that the electrostatic model associated with the dipole-dipole interactions, the Pauli exchange-type repulsions, and the hyperconjugative interactions are in favor of the gauche-conformation of compound 1. Since the results of this work and previously published data ${ }^{19,20}$ indicate that there is a small energy difference between the gauche- and anti-conformations of compound $\mathbf{1}$, we suggest a re-evaluation of the conformational properties of compound 1 by spectroscopic techniques (e.g., gas electron diffraction or microwave spectroscopy).

Importantly, the transition state structures of the retro-ene decomposition reactions of compounds 1-3 possess smaller dipole moments compared to their corresponding gaucheconformations. Based on the calculated dipole moments for the transition state and the gauche-conformations, the $\Delta[\mu(\mathrm{TS})-$ $\mu($ gauche $)]$ parameters for compounds 1-3 possess negative values and slightly increase from compound $\mathbf{1}$ to compound $\mathbf{3}$, revealing that the rationalization of the retro-ene decomposition reactions solely in terms of the electrostatic model associated with the dipole-dipole interaction fails to fully account for compounds 1-3. This fact contradicts the conclusions proposed by some researchers who claimed that "the isomer with larger molecular dipole moment is the less stable one". ${ }^{35}$

\section{Kinetic parameters of the retro-ene decomposition reactions of compounds $1-3$}

The kinetic parameters of the retro-ene decomposition reactions of compounds 1-3 were estimated using the classical transition state theory (TST). ${ }^{79,80}$ The Eyring-Polanyi equation was used to estimate the temperature-dependent rate constant $[k(T)]$ of the retro-ene decomposition reactions of compounds 1-3 (eqn (6)):

$$
k(T)=\frac{k_{\mathrm{B}} T}{h} \mathrm{e}^{\frac{-\Delta G^{\neq}(T)}{R T}}
$$

where $k_{\mathrm{B}}, R$, and $h$ are the Boltzmann constant, the universal gas constant, and the Planck constant, respectively, and the transmission coefficient was assumed to be equal to unity. The temperature-dependent rate constants $[k(T)]$ of the retro-ene decomposition reactions of compounds 1-3 were estimated at different temperatures $(300,400,500$, and $600 \mathrm{~K})$. The MP2/6$311++\mathrm{G}^{* *}$ results showed that the temperature-dependent rate constant $[k(T)]$ of the retro-ene decomposition reaction of compound 1 was greater $\left(10^{6}\right.$ times) than that of compounds 2 and 3 (Table ESI- $4 \dagger$ ). The results obtained showed that the rate constants of the retro-ene decomposition reactions of compounds 1-3 increase drastically with the increase in the temperature. The constants of the retro-ene decomposition reactions of compounds 1-3 at $600 \mathrm{~K}$ are much greater than those at ambient temperature. In accordance with the TST, the activation energy $\left(E_{\mathrm{a}}\right)$ and the Arrhenius $A$ factor were calculated by the following equations, respectively (eqn (7) and (8)):

$$
\begin{gathered}
E_{\mathrm{a}}=\Delta H^{\neq}(T)+R T \\
A=\frac{e k_{\mathrm{B}} T}{h} \mathrm{e}^{\frac{\Delta S^{\neq}(T)}{R}}
\end{gathered}
$$

The activation energy $\left(E_{\mathrm{a}}\right)$ for the retro-ene decomposition reactions increases drastically from compound $\mathbf{1}$ to compound 2 , but does not change significantly going from compound 2 to compound 3 (Table 6). Interestingly, the results obtained showed that the calculated Arrhenius $A$ factors for the retro-ene decomposition reactions of compounds 1-3 are relatively the same and fall within the range $10^{11.5}$ to $10^{14.5} \mathrm{~s}^{-1}$, which is acceptable for such unimolecular reactions. ${ }^{81}$

The calculated entropies of activation $\left(\Delta S^{\neq}\right)$for the retro-ene decomposition reactions of compounds 1-3 were used in support of the reaction mechanisms occurring via a concerted six-membered cyclic transition state (Table 6). The calculated activation entropies $\left(\Delta S^{\neq}\right)$of the retro-ene decomposition of compounds 1-3 lie between -7.00 and $7.00 \mathrm{cal} \mathrm{mol}^{-1} \mathrm{~K}^{-1}$, demonstrating that their calculated Arrhenius factors are normal. The $\Delta S^{\neq}$value of the retro-ene decomposition reactions decrease when going from compound 1 to compound 3. By considering the calculated $\Delta S^{\neq}$values of the retro-ene decomposition reactions of compounds 1-3, we can expect 
Table 6 MP2/6-311++G** calculated activation energies $\left(E_{\mathrm{a}}\right.$, in kcal mol $\left.{ }^{-1}\right)$, Arrhenius factors $\left(A\right.$, in $\left.\mathrm{s}^{-1}\right)$, rate constants $\left(k\right.$, in $\left.\mathrm{s}^{-1}\right)$, activation enthalpies $\left(\Delta H^{\neq}\right.$, in $\left.\mathrm{kcal} \mathrm{mol}^{-1}\right)$, activation entropies $\left(\Delta S^{\neq}\right.$, in cal mol $\left.{ }^{-1} \mathrm{~K}^{-1}\right)$, activation Gibbs free energies $\left(\Delta G^{\neq}\right.$, in $\left.\mathrm{kcal}^{\mathrm{mol}} \mathrm{l}^{-1}\right)$, and thermodynamic parameters $\left(\Delta H=H_{p}-H_{G S}\right.$ and $\Delta G=G_{p}-G_{G s}$ : in kcal mol ${ }^{-1}, \Delta S=S_{p}-S_{G s}$ : cal mol $\left.{ }^{-1} \mathrm{~K}^{-1}\right)$ of the decomposition reactions of compounds $1-3$ at $300 \mathrm{~K}$

\begin{tabular}{|c|c|c|c|c|c|c|c|c|c|}
\hline & \multicolumn{9}{|c|}{ MP2/6-311++G** } \\
\hline 1-gauche $\rightarrow[\mathrm{TS}]^{\neq} \rightarrow \mathbf{1 - P}$ & 31.38 & $3.07 \times 10^{12}$ & $2.51 \times 10^{-11}$ & 30.79 & -3.373 & 31.80 & -6.49 & 35.667 & -17.12 \\
\hline 2-gauche $\rightarrow[\mathrm{TS}]^{\neq} \rightarrow 2$-P & 39.98 & $2.44 \times 10^{12}$ & $9.45 \times 10^{-18}$ & 39.39 & -3.829 & 40.53 & 20.25 & 34.088 & 10.09 \\
\hline
\end{tabular}

their transition state structures to have significantly greater rigidity than their corresponding initial states. Accordingly, the transition state structures of the retro-ene decomposition reactions of compounds 1-3 had much less freedom of vibrations than their corresponding initial states.

\section{Conclusion}

The results obtained at the MP2/6-311++G** and G3(MP2) levels of theory and the natural bond orbital (NBO) interpretations provided a reasonable picture from an energetic, structural, bonding, and stereoelectronic point of view for the conformational preferences in compounds 1-3 and their corresponding retro-ene decomposition reactions. The role and contributions of the hyperconjugative interactions on the conformations preferences of compounds 1-3 were assessed by the deletion of the overlapping orbitals [which are changed by the rotations around the $\mathrm{M}-\mathrm{CH}_{2}$ bond $[\mathrm{M}=\mathrm{O}(\mathbf{1}), \mathrm{M}=\mathrm{S}(2), \mathrm{M}=\mathrm{Se}(3)]$ from the Fock matrices of the gauche- and anti-conformations. Based on the results obtained, the deletion of the hyperconjugative interactions mentioned above from the Fock matrices leads to an increase in the preference for the anti-conformation, demonstrating the significant impacts of the hyperconjugative interactions on the gauche-conformation preferences in compounds 1-3. The electrostatic model associated with the dipole-dipole interactions is in favor of the gauche-conformations of compounds $\mathbf{1 - 3}$, but does not justify the potential energy surfaces of the retro-ene decomposition reactions of compounds 1-3.

Since the hyperconjugative interactions, the electrostatic model associated with the dipole-dipole interactions, and steric effects are in favor of the gauche-conformation of compound $\mathbf{1}$, no fact justifies the anti-conformation preference in compound 1. Accordingly, we claim that there is some doubt concerning the interpretations of the rotational spectra of compound $\mathbf{1}$. As experimental data (infrared spectroscopy) ${ }^{20}$ indicated the presence of two forms (gauche- and anti-conformations), we suggest a re-evaluation of the conformational and structural properties of compound 1 by gas electron diffraction or microwave spectroscopy to be carried out with more consciousness.

In accordance with the results of this work and the previously published theoretical data, ${ }^{20,21}$ compounds 1-3 were found to be stable in the gas phase and their corresponding cyanate $\rightarrow$ isocyanate unimolecular isomerization reactions could not take place at ambient temperature. Based on the results of this work, the retro-ene decomposition reactions of compounds 1-3 will occur earlier than their corresponding unimolecular cyanate $\rightarrow$ isocyanate unimolecular isomerization reactions. Importantly, the exchange component has a determining role on the retro-ene decomposition reactions of these compounds. The calculated potential energy surfaces and the advancements of the transition states $\left(\delta B_{\mathrm{av}}\right)$ of the retro-ene decomposition reactions of compounds 1-3 are in agreement with the Hammond-Leffler postulate. The greater overall synchronicities of the retro-ene decomposition reactions of compounds 2 and 3 compared to that of compound 1 results from the greater attractive electrostatic interactions between the two adjacent $\mathrm{S}_{3}-\mathrm{C}_{4}$ and $\mathrm{Se}_{3}-\mathrm{C}_{4}$ atoms in compounds 2 and $\mathbf{3}$, respectively, in comparison to the smaller one (i.e., $\mathrm{O}_{3}-\mathrm{C}_{4}$ ) in compound 1.

Since the $\mathrm{X}_{3}-\mathrm{C}_{4}$ bonds break in the transition state structures of the retro-ene decomposition reactions of compounds $1-3$, we decomposed the hyperconjugative generalized anomeric effects $\left(\right.$ HCGAE $\left._{\text {total }}\right)$ (which have impacts on the strengthening or weakening of the $\mathrm{X}_{3}-\mathrm{C}_{4}$ bonds) into two components. Most interestingly, the variations of $\Delta\left[\operatorname{HCGAE}\left(\mathrm{X}_{3}-\mathrm{C}_{4}\right.\right.$ weakening $)-$ $\operatorname{HCGAE}\left(\mathrm{X}_{3}-\mathrm{C}_{4}\right.$ strengthening)] parameters correlated well with the variations of the retro-ene decomposition reactions barrier heights when going from compound $\mathbf{1}$ to compound $\mathbf{3}$. Based on this finding, this procedure could be an applicable and suitable approach to investigate the feasibility of various chemical reactions (especially unimolecular reactions).

\section{References}

1 J. Gonda, M. Martinkova, J. Raschmanova and E. Balentova, Tetrahedron: Asymmetry, 2006, 17, 1875.

2 J. Burmeister, Coord. Chem. Rev., 1990, 105, 77.

3 T. Castanheiro, J. Suffert, M. Donnard and M. Gulea, Chem. Soc. Rev., 2016, 45, 494.

4 C. Johansen, P. Falholt and L. Gram, Appl. Environ. Microbiol., 1997, 63, 3724.

5 L. Bjorck, C. Rosen, V. Marshall and B. Reiter, Appl. Microbiol., 1975, 30, 199.

6 B. Reiter, V. M. Marshall, L. Bjorck and C. G. Rosen, Infect. Immun., 1976, 13, 800. 
7 D. Plano, Y. Baquedano, D. Moreno-Mateos, M. Font, A. Jiménez-Ruiz, J. A. Palop and C. Sanmartín, Eur. J. Med. Chem., 2011, 46, 3315.

8 E. Riedle and H. Mayr, Chem.-Eur. J., 2008, 14, 3866.

9 D. A. Ben-Efraim, in The Chemistry of Cyanates and Their Thio Derivatives, ed. S. Patai, Wiley, Chichester, 1977.

10 S. S. Al-Juaid, A. A. K. Al-Nasr, G. A. Ayoko, C. Eaborn and P. Hitchcock, J. Organomet. Chem., 1995, 488, 155.

11 C. Eaborn, P. D. Lickiss, G. Markuina-Chidsey and E. Y. Thorli, J. Chem. Soc., Chem. Commun., 1982, 1326.

12 D. Martin, Tetrahedron Lett., 1964, 39, 2829.

13 A. Holm and E. Huge-Jensen, Acta Chem. Scand., Ser. B, 1974, 28, 705.

14 H. Fischer, S. Zeuner, K. Ackermann and U. Schubert, J. Organomet. Chem., 1984, 263, 201.

15 P. Reich and D. Martin, Chem. Ber., 1965, 98, 2063.

16 N. Groving and A. Holm, Acta Chem. Scand., 1965, 19, 443.

17 K. A. Jensen, A. Holm and C. Wentrup, Acta Chem. Scand., 1966, 20, 2107.

18 T. Sakaizumi, H. Mure, O. Ohashi and I. Yamaguchi, J. Mol. Spectrosc., 1989, 138, 375.

19 J. Urban, A. Nowek, R. Venkatraman, P. Babinec and J. Leszczynski, Struct. Chem., 1998, 9, 161.

20 T. Pasinszki, B. Havasi and A. Kovács, J. Phys. Chem. A, 2003, 107, 1720.

21 V. I. Faustov, E. G. Baskir and A. A. Biryukov, Russ. Chem. Bull., Int. Ed., 2003, 52, 2328.

22 R. P. Hirschmann, R. N. Kniseley and V. A. Fassel, Spectrochim. Acta, 1964, 20, 809.

23 A. Bjørseth and K. M. Marstokk, J. Mol. Struct., 1972, 11, 15. 24 O. H. Ellestad and T. Torgrimsen, J. Mol. Struct., 1972, 12, 79.

25 J. R. Durig, J. F. Sullivan and H. L. Heusel, J. Phys. Chem., 1984, 88, 374 .

26 G. O. Braathen and A. Gatial, Spectrochim. Acta, Part A, 1986, $42,615$.

27 T. Sakaizumi and T. Itakura, J. Mol. Spectrosc., 1994, 163, 1.

28 P. A. Petillo and L. E. Lerner, in The Anomeric Effect and Associated Steroelectronic Effects, ed. G. R. J. Thacher, American Chemical Society, ACS Symposium Series No. 539, Washington, DC, 1993.

29 A. Behrouz and D. Nori-Shargh, Aust. J. Chem., 2016, 70, 61. $30 \mathrm{~J}$. Kirby, The Anomeric Effect and Related Stereoelectronic Effects at Oxygen, Springer Verlag, New York, NY, 1983.

$31 \mathrm{P}$. Deslongchamps, Stereoelectronic Effects in Organic Chemistry, Wiley, New York, NY, 1983.

32 E. Juaristi and G. Cuevas, The Anomeric Effect, CRC Press Inc., Boca Raton, FL, 1995.

33 C. J. Cramer, J. Org. Chem., 1992, 57, 7034.

34 C. J. Cramer, D. G. Truhlar and A. D. French, Carbohydr. Res., 1997, 298, 1.

35 C. L. Perrin, K. B. Armstrong and M. A. Fabian, J. Am. Chem. Soc., 1994, 116, 715.

36 A. Lesarri, A. Vega-Toribio, R. D. Suenram, D. J. Brugh, D. Nori-Shargh, J. E. Boggs and J.-U. Grabow, Phys. Chem. Chem. Phys., 2011, 13, 6610.

37 A. Vila and R. A. Mosquera, J. Comput. Chem., 2007, 28, 1516. 38 S. Hosseini and D. Nori-Shargh, Can. J. Chem., 2016, 94, 176.
39 E. Juaristi and R. Notario, J. Org. Chem., 2016, 81, 192.

40 J. P. Praly and R. U. Lemieux, Can. J. Chem., 1987, 65, 213.

41 D. Nori-Shargh, S. N. Mousavi and H. Kayi, J. Mol. Model., 2014, 20, 2249.

42 M. P. Freitas, Org. Biomol. Chem., 2013, 11, 2885.

43 T. M. Barbosa, R. V. Viesser, R. J. Abraham, R. Rittner and C. F. Tormena, $R S C$ Adv., 2015, 5, 35412.

44 P. Ghanbarpoura and D. Nori-Shargh, RSC Adv., 2016, 6, 46406.

45 G. F. Bauerfeldt, T. M. Cardozo, M. S. Pereira and C. O. da Silva, Org. Biomol. Chem., 2013, 11, 299.

46 N. Hasanzadeh, D. Nori-Shargh, M. Farzipour and B. Ahmadi, Org. Biomol. Chem., 2015, 13, 6965.

47 D. Nori-Shargh, S. N. Mousavi, R. Tale and H. Yahyaei, Struct. Chem., 2016, 27, 1753.

48 I. V. Alabugin, J. Org. Chem., 2000, 65, 3910.

49 J. K. Badenhoop and F. Weinhold, J. Chem. Phys., 1997, 107, 5406.

50 J. K. Badenhoop and F. Weinhold, J. Chem. Phys., 1997, 107, 5422.

51 J. K. Badenhoop and F. Weinhold, Int. J. Quantum Chem., 1999, 72, 269.

52 V. F. Weisskopf, Science, 1975, 187, 605.

53 P. A. Christiansen and W. E. Palke, J. Chem. Phys., 1977, 67, 57.

54 L. A. Curtiss, P. C. Redfern, K. Raghavachari, V. Rassolov and J. A. Pople, J. Chem. Phys., 1999, 110, 4703.

55 C. Møller and M. S. Plesset, Phys. Rev., 1934, 46, 618.

56 D. Cremer, in Encyclopedia of Computational Chemistry, ed.

P. V. R. Schleyer, N. L. Allinger, T. Clark, J. Gasteiger, P. A. Kollma, H. F. Schaefer III and P. R., Schreiner, John Wiley, Chichester, 1998.

57 W. J. Hehre, L. Radom, P. V. R. Schleyer and J. A. Pople, $A b$ Initio Molecular Orbital Theory, Wiley, New York, 1986.

58 A. D. McLean and G. S. Chandler, J. Chem. Phys., 1980, 72, 5639.

59 R. Krishnan, J. S. Binkley, R. Seeger and J. A. Pople, J. Chem. Phys., 1980, 72, 650.

60 J.-P. Blaudeau, M. P. McGrath, L. A. Curtiss and L. Radom, J. Chem. Phys., 1997, 107, 5016.

61 A. J. H. Wachters, J. Chem. Phys., 1970, 52, 1033.

62 P. J. Hay, J. Chem. Phys., 1977, 66, 4377.

63 R. C. Binning Jr and L. A. Curtiss, J. Comput. Chem., 1990, 11, 1206.

64 L. A. Curtiss, M. P. McGrath, J. P. Blandeau, N. E. Davis, R. C. Binning Jr and L. Radom, J. Chem. Phys., 1995, 103, 6104.

65 M. P. McGrath and L. Radom, J. Chem. Phys., 1991, 94, 511. 66 M. W. Schmidt, K. K. Baldridge, J. A. Boatz, S. T. Elbert, M. S. Gordon, J. H. Jensen, S. Koseki, N. Matsunaga, K. A. Su, S. J. Nguyen, T. L. Windus, M. Dupuis and J. A. Montgomery Jr, J. Comput. Chem., 1993, 14, 1347.

67 M. S. Gordon and M. W. Schmidt, Advances in electronic structure theory: GAMESS a decade later, in Theory and Applications of Computational Chemistry, the first 40 years, C. E. Dykstra, G. Frenking, K. S. Lim and G. E. Scusaria, Amsterdam, Elsevier, 2005. 
68 E. D. Glendening, J. K. Badenhoop, A. E. Reed, J. E. Carpenter, J. A. Bohmann, C. M. Morales and F. Weinhold, NBO Version 5.G., Theoretical Chemistry Institute, University of Wisconsin, Madison, WI, 2004.

69 N. D. Epiotis, R. L. Yates, R. J. Larson, C. R. Kirmayer and F. Bernardi, J. Am. Chem. Soc., 1977, 99, 8379.

70 M. J. S. Dewar, The Molecular Orbital Theory of Organic Chemistry, McGraw-Hill, New York, 1969.

71 W. T. Borden, Modern Molecular Orbital Theory for Organic Chemists, Prentice-Hall, Englewood Cliffs, NJ, 1975.

72 M. Wolfsberg and L. Helmholz, J. Chem. Phys., 1952, 20, 837.

73 D. D. Radtke and R. F. Fenske, J. Am. Chem. Soc., 1967, 89, 2292.

74 F. Weinhold, in Encyclopedia of Computational Chemistry, ed. P. V. R. Schleyer, N. L. Allinger, T. Clark, J. Gasteiger, P. A.
Kollman, H. F. Schaefer III and P. R. Schreiner, Wiley, Chichester, U.K., 1998.

75 A. Moyano, M. A. Pericas and E. Valenti, J. Org. Chem., 1989, $54,573$.

76 O. N. Faza, C. S. López and I. Fernández, J. Org. Chem., 2013, 78, 5669.

77 L. R. Domingo, M. J. Aurell, P. Pérez and R. Contreras, J. Org. Chem., 2003, 68, 3884.

78 E. Chamorro, J. Quijano, R. Notario, C. Sánchez, L. A. León and G. Chuchani, Int. J. Quantum Chem., 2003, 91, 618.

79 K. J. Glasstone, K. J. Laidler and H. Eyring, The theory of rate processes, McGraw-Hill, New York, 1941.

$80 \mathrm{~S}$. W. Benson, The foundations of chemical kinetics, McGrawHill, New York, 1969.

81 B. G. Gowenlock, Q. Rev., Chem. Soc., 1960, 14, 133. 